\title{
RANK- and c-Met-mediated signal network promotes prostate cancer metastatic colonization
}

\author{
Gina Chia-Yi Chu', Haiyen E Zhau', Ruoxiang Wang', André Rogatko ${ }^{3,4}$, Xu Feng ${ }^{5}$, \\ Majd Zayzafoon ${ }^{5}$, Youhua Liu ${ }^{6}$, Mary C Farach-Carson? ${ }^{7}$ Sungyong You ${ }^{2,3}$, \\ Jayoung Kim ${ }^{2,3}$, Michael R Freeman ${ }^{1,2,3}$ and Leland W K Chung ${ }^{1,2}$ \\ 'Uro-Oncology Research, Department of Medicine, Samuel Oschin Comprehensive Cancer Center, \\ Cedars-Sinai Medical Center, 8750 Beverly Blvd., Atrium 103, Los Angeles, California 90048, USA \\ Departments of ${ }^{2}$ Surgery ${ }^{3}$ Biomedical Sciences ${ }^{4}$ Biostatistics and Bioinformatics Center, Samuel Oschin \\ Comprehensive Cancer Center, Cedars-Sinai Medical Center, Los Angeles, California, USA \\ ${ }^{5}$ Department of Pathology, School of Medicine, University of Alabama, Birmingham, Alabama, USA \\ ${ }^{6}$ Department of Pathology, University of Pittsburgh, Pittsburgh, Pennsylvania, USA \\ ${ }^{7}$ Department of Biochemistry and Cell Biology, Rice University, Houston, Texas, USA
}

Correspondence should be addressed to L W K Chung

Email

Leland.chung@cshs.org

\begin{abstract}
Prostate cancer ( $\mathrm{PCa}$ ) metastasis to bone is lethal and there is no adequate animal model for studying the mechanisms underlying the metastatic process. Here, we report that receptor activator of NF- $\kappa B$ ligand (RANKL) expressed by PCa cells consistently induced colonization or metastasis to bone in animal models. RANK-mediated signaling established a premetastatic niche through a feed-forward loop, involving the induction of RANKL and c-Met, but repression of androgen receptor (AR) expression and AR signaling pathways. Site-directed mutagenesis and transcription factor (TF) deletion/interference assays identified common TF complexes, c-Myc/Max, and AP4 as critical regulatory nodes. RANKL-RANK signaling activated a number of master regulator TFs that control the epithelial-to-mesenchymal transition (Twist1, Slug, Zeb1, and Zeb2), stem cell properties (Sox2, Myc, Oct3/4, and Nanog), neuroendocrine differentiation (Sox9, HIF1 $\alpha$, and FoxA2), and osteomimicry (c-Myc/Max, Sox2, Sox9, HIF1 $\alpha$, and Runx2). Abrogating RANK or its downstream c-Myc/Max or c-Met signaling network minimized or abolished skeletal metastasis in mice. RANKL-expressing LNCaP cells recruited and induced neighboring non metastatic LNCaP cells to express RANKL, c-Met/activated c-Met, while downregulating AR expression. These initially non-metastatic cells, once retrieved from the tumors, acquired the potential to colonize and grow in bone. These findings identify a novel mechanism of tumor growth in bone that involves tumor cell reprogramming via RANK-RANKL signaling, as well as a form of signal amplification that mediates recruitment and stable transformation of non-metastatic bystander dormant cells.
\end{abstract}

\author{
Key Words \\ - RANKL \\ - RANK \\ - c-Met \\ - prostate cancer \\ - metastasis \\ - cancer dormancy
}

\section{Introduction}

Bone is the most common site of prostate cancer (PCa) metastases. Metastatic lesions in bone are significantly associated with bone pain, hypercalcemia or hypocalcemia, pathological fracture, and spinal cord compression (Coleman 2001). Receptor activator of NF- $\kappa \mathrm{B}$ ligand (RANKL)-RANK signaling has many crucial http://erc.endocrinology-journals.org DOI: 10.1530/ERC-13-0548
(C) 2014 The authors Published by Bioscientifica Ltd. Printed in Great Britain
Endocrine-Related Cancer

(2014) 21, 311-326 
physiological roles in bone and other tissues (Hanada et al. 2009), and aberrant RANKL-RANK signaling in cancer and bone cells affects cancer bone colonization (Dougall $2011)$. We reported previously that $\beta 2$-microglobulin $(\beta 2-\mathrm{M})$, a major histocompatibility protein co-receptor, promotes PCa cell osteomimicry by inducing RANKL and non-collagenous bone matrix proteins (Huang et al. 2006, Odero-Marah et al. 2008). $\beta 2$-M-induced RANKL expression promoted epithelial-to-mesenchymal transition (EMT) in PCa cells (Zhau et al. 2008). Forced expression of $\beta 2-\mathrm{M}$ in non-metastatic human breast, lung, and kidney cancer cells enhanced endogenous RANKL expression and induced EMT and bone and soft tissue homing (Josson et al. 2011). These findings support an important role for RANKL-RANK signaling in PCa metastasis.

Hepatocyte growth factor (HGF) and its receptor tyrosine kinase c-Met mediate cell motility, migration, increased tumor local invasion, and metastasis (Knudsen \& Edlund 2004). Deregulation of the c-Met network is one of the most common mechanisms of solid tumor development (Birchmeier et al. 2003). The c-Met receptor cross talks with many membrane-localized signaling proteins, including EGFR, erbB2, erbB3, c-Src, and G-protein-coupled receptors, indicating the existence of numerous mechanisms of tumor cell escape from therapies directed at single oncogenic targets (Organ \& Tsao 2011). c-Met inhibitors with differential selectivity have been developed based on their relative ATP competitive binding. Cabozantinib (XL-184), a recently FDA approved mixed c-Met, VEGFR2, KIT, and AXL inhibitor, proved highly effective against bone metastatic PCa (Smith et al. 2013). c-Met activation can be ligand-dependent or -independent and is associated with androgen receptor (AR)-deficient castration-resistant prostate cancer (CRPC; Verras et al. 2007) and AR-negative PCa stem cells (van Leenders et al. 2011).

Here, we describe a feed-forward loop, involving the induction of RANKL and c-Met signal and repression of AR, which drives RANK receptor-mediated bone metastasis. Novel RANK-mediated downstream master regulator (MR) transcription factors (TFs) were identified that coordinate PCa cell EMT, stemness, neuroendocrine, and osteomimicry phenotypes. We validated the roles of TFs and effector molecules in PCa metastasis with in vivo animal models guided by molecular imaging where abrogating RANK or its downstream c-Myc/Max or c-Met signaling network abolished skeletal metastasis in mice. Animal models also showed that RANKL-expressing PCa cells conferred bone colonizing and aggressive phenotypes to neighboring non-metastatic bystander cells by activating the RANK-mediated downstream signaling network. Significantly, RANKL and its downstream signaling network in primary human PCa tissues predict patient survival (Hu et al. 2013).

\section{Subjects and methods}

\section{Cell culture}

$\mathrm{ARCaP}_{\mathrm{E}}$ and $\mathrm{ARCaP}_{\mathrm{M}}$ cells established by our laboratory (Xu et al. 2006) represent stages of human PCa progression. They were maintained in T-medium (Invitrogen) supplemented with $5 \%$ FBS. LNCaP and $\mathrm{LNCaP}^{\mathrm{Neo} / \mathrm{RANKL}}$ were maintained in RPMI-1640 supplemented with 10\% FBS. RAW264.7 cells, provided by Dr Neale Weitzmann at Emory University, were maintained in DMEM supplemented by $10 \%$ FBS.

\section{Cloning RANKL expression vectors}

Human RANKL cDNA ORF (NM_003701) purchased from OriGene (Rockville, MD, USA) was amplified by PCR and subcloned into p3 $\times$ FLAG-myc-CMV-25 (Sigma-Aldrich) at the NotI and XbaI restriction enzyme sites. The amplified human RANKL cDNA was subcloned into pCDH-CMV-MCS-EF1-copGFP (System Biosciences, Mountain View, CA, USA) plasmids at the XbaI and NotI restriction enzyme sites. The sequences of $\mathrm{p} 3 \times \mathrm{FLAG}$ RANKL and pCDH-CMV-RANKL-EF1-CopGFP were confirmed by DNA sequencing.

\section{Cell transfection, transduction, and gene deletion protocols}

LNCaP cells were transfected with either $\mathrm{p} 3 \times$ Flag-tagged RANKL or neo-control-plasmid (p3 $\times$ FLAG-myc-CMV-25) cDNA (Sigma-Aldrich) for $48 \mathrm{~h}$. The stable cell clones were selected in $400 \mu \mathrm{g} / \mathrm{ml}$ of $\mathrm{G} 418$ until individual colonies containing the transfected construct were confirmed by western blot analysis. The retrovirus packaging cells, 293GPG, were maintained in DMEM with 10\% heatinactivated FBS supplemented with tetracycline, puromycin, G418, and penicillin/streptomycin. The shRANK-1 and -4 retroviruses were generated using the retroviral small interfering RNA (siRNA) constructs pPower-hRK-1 (hRK-1) and pPower-hRK-4 (hRK-4) prepared using standard molecular cloning techniques and were used to infect $\mathrm{ARCaP}_{\mathrm{M}}$ and $\mathrm{LN}^{\mathrm{RANKL}}$ cells for $24 \mathrm{~h}$ in the presence of $8 \mu \mathrm{g} / \mathrm{ml}$ of polybrene. The oligosequences of RANK and control short hairpin RNA (shRNA) are as follows: shRANK-1, CCAGAAGATATGTGCTACCCA; shRANK-4, TGGGACGGTGCTGTAACAAA; and shCon,

Published by Bioscientifica Ltd 
ACCATCTTAGTAGAGGTTGTT. The transfected cells as well as parental and tumor-derived $\mathrm{LN}^{\mathrm{Neo}-\mathrm{RFP}}$ cells were also transduced with firefly luciferase retroviruses (MSCV Luciferase PGK Hygro; Addgene, Cambridge, MA, USA) and selected with $200 \mu \mathrm{g} / \mathrm{ml}$ hygromycin. To evaluate the possible functions of key receptors and TFs in PCa metastasis, we conducted genetic deletion studies of c-Met and c-Myc and/or Max from LN ${ }^{\text {RANKL }}$ cells. c-Myc (sc-29226-V) and Max (sc-38080-V) shRNA viral particles were purchased from Santa Cruz Biotechnology, Inc. and c-Met shRNA viral particles (TRCN0000009851, TRCN0000040044, and TRCN0000121087) were purchased from Sigma-Aldrich.

\section{In vivo experiments}

All animal procedures were performed according to an approved protocol from the Institutional Animal Care and Use Committee. $\mathrm{LN}^{\mathrm{RANKL}}$, $\mathrm{LN}^{\mathrm{Neo}}$, or $\mathrm{LN}^{\mathrm{Neo}-\mathrm{RFP}}$ cells $\left(1 \times 10^{6}\right.$ cells/50 $\mu \mathrm{l} \mathrm{PBS}$ ) were tagged with the luciferase gene and inoculated intracardially or intratibially into 5- to 7-weekold male athymic nude mice (Charles River, Wilmington, MA, USA) as described previously (Odero-Marah et al. 2008). To study their interactions and recruitment, in some studies, cells were injected together or separately at different ratios or by a separate route. All mice were imaged weekly with either bioluminescence or fluorescence (red fluorescent protein (RFP): excitation, $570 \mathrm{~nm}$; emission, $620 \mathrm{~nm}$; a near-infrared MHI-148 organic dye: excitation, $783 \mathrm{~nm}$; emission, $840 \mathrm{~nm}$ (Yang et al. 2010)) using Xenogen and scanned by X-ray by Luminar XR or X-ray microtomography $(\mu \mathrm{CT})$ by Scanco vivaCT40 to examine the skeleton and determine the types of bone lesions.

\section{RT-PCR and quantitative real-time PCR}

Total RNA from cells was isolated using an RNeasy Mini Kit (Qiagen) according to the manufacturer's instructions. cDNA was generated from $3 \mu \mathrm{g}$ of total RNA using a SuperScript III First-Strand Synthesis System (Invitrogen), Quantitative real-time PCR was performed by the ABI 7500 Fast system in a total of $20 \mu \mathrm{l}$ of reaction containing $1 \mu \mathrm{l}$ cDNA, $1 \mu \mathrm{l}$ primer pairs, $8 \mu \mathrm{l}$ ABI SYBR Green Master Mix (Applied Biosystems), and $8 \mu \mathrm{l}$ RNAse-free water, and run at $95^{\circ} \mathrm{C}, 3 \mathrm{~min}$, followed by 40 cycles of $95^{\circ} \mathrm{C}, 30 \mathrm{~s}$ and $60^{\circ} \mathrm{C}$, 30 s. Real-time PCR primer sequences are listed in Table 1.

\section{Western blot analysis}

Proteins $(30 \mu \mathrm{g})$ were resolved on a $4-12 \%$ Bis-Tris gradient SDS-PAGE under reducing conditions and transferred onto

Table 1 Real-time PCR primer sequences

Genes

RANKL

RANK

OPG

E-cadherin

$N$-cadherin

Vimentin

c-Myc

c-Met

CD44

CD133

CD49f

OCT4

SOX2

Nanog

Lin28b

SYP

$\operatorname{CgA}$

FOXA2

SOX2

$A R$

Real-time PCR primer sequences

F: $5^{\prime}$-TCCCATCTGGTTCCCATAAA- $3^{\prime}$

R: $5^{\prime}$-GGTGCTTCCTCCTTTCATCA-3'

F: $5^{\prime}$-GTCTGGAAGCTCCCCTGGT-3'

R: 5'-TTGAAGTTCATCACCTGCCC-3'

F: $5^{\prime}$-TTCCGGAAACAGTGAATCAA-3'

R: $5^{\prime}$-CGCTGTTTTCACAGAGGTCA-3'

F: 5'-CCCGGGACAACGTTTATTAC-3'

R: 5'-GCTGGCTCAAGTCAAAGTCC-3'

F: $5^{\prime}$-GGTGGAGGAGAAGAAGACCAG-3'

R: 5'-GGCATCAGGCTCCACAGT-3'

F: $5^{\prime}$-GGAAGAGAACTTTGCCGTTGAA-3'

R: 5'-GTGACGAGCCATTTCCTCCTT-3'

F: $5^{\prime}$-TCAAGAGGCGAACACACAAC-3'

R: $5^{\prime}$-GGCCTTTTCATTGTTTTCCA-3'

F: 5'-TGAAATTCATCCAACCAAATCTT-3'

R: 5'-AATAGAAAACTGACAATGTTGAGAGG-3'

F: $5^{\prime}$-TCAGAGGAGTAGGAGAGAGGAAAC-3'

R: $5^{\prime}$-GAAAAGTCAAAGTAACAATAACAGTGG-3'

F: 5'-CAGAGTACAACGCCAAACCA-3'

R: 5'-AAATCACGATGAGGGTCAGC-3'

F: $5^{\prime}$-TTGGAGCTCCGTATGATGACTTGG-3'

R: 5'-GGATCTCCACTGAGGCAGTTATGG-3'

F: 5'-AGCAAAACCCGGAGGAGT-3'

R: $5^{\prime}$-CCACATCGGCCTGTGTATATC- $3^{\prime}$

F: $5^{\prime}$-TTGCTGCCTCTTTAAGACTAGGA-3'

R: 5'-CTGGGGCTCAAACTTCTCTC-3'

F: 5'-ATGCCTCACACGGAGACTGT-3'

R: $5^{\prime}$-AAGTGGGTTGTTTGCCTTTG-3'

F: $5^{\prime}$-CTGTCAGAGCATCATGCACATG-3'

R: 5'-GGGTGGCTGTGCAACATTTT-3'

F: $5^{\prime}$-TGCGCTAGAGCATTCTGGG-3'

R 5'-CTTAAAGCCCTGGCCCCTTCT-3'

F: 5'-CCCCACTGTAGTGCTGAACC-3'

R: $5^{\prime}$-GGAGTGCTCCTGTTCTCCC-3'

F: 5'-TCTTAAGAAGACGACGGCTTCAG-3'

R: $5^{\prime}$-TTGCTCTCTCACTTGTCCTCGAT-3'

F: $5^{\prime}$-TTGCTGCCTCTTTAAGACTAGGA-3'

R: $5^{\prime}$-CTGGGGCTCAAACTTCTCTC-3'

F: $5^{\prime}$-GACCAGATGGCTGTCATTCA-3'

R: 5'-GGAGCCATCCAAACTCTTGA-3'

nitrocellulose membrane. The primary antibodies were RANKL, E-cadherin, vimentin, OPG, c-Met (Santa Cruz Biotechnology, Inc.), p-c-Met (Tyr-1230/34/35; Invitrogen), RANK (Amgen, Thousand Oaks, CA, USA), and N-cadherin (BD Transduction Laboratories, San Jose, CA, USA). AR (441), Chr-A (H-300), synaptophysin (SYP; D4), CD44 (DF1485), Sox-2 (Y-17), Nanog (5A10), LIN-28 (H-44) (Santa Cruz Biotechnology, Inc.), FOXA2 (D56D6; Cell Signaling Technology, Danvers, MA, USA), and PROM1 (CD133; Abnova, Taipei City, Taiwan) antibodies were used to detect neuroendocrine and stem cell differentiation. c-Myc (D84C12XP), Lamin A/C (Cell Signaling Technology), and Max (sc-197X) antibodies (Santa Cruz Biotechnology, Inc.) were used for nuclear protein detection.

Published by Bioscientifica Ltd. 


\section{Immunohistochemistry}

Human PCa tissue arrays in FFPE were purchased from Invitrogen and the PCa bone metastasis array (UWTMA22) was kindly provided by Dr Robert L Vessella from the University of Washington (Seattle, WA, USA). Immunohistochemical (IHC) staining followed a previously published protocol (Zhau et al. 2008) using primary antibodies against RANKL FL-317, c-Met C-12 (Santa Cruz Biotechnology, Inc.), and p-c-Met (pYpYpY1230/1234/1235; Invitrogen). IHC staining intensity was scored using the combined intensity and percentage of positive-scoring cells as previously reported (De Marzo et al. 1999). Strong intensity was scored as 3 , intermediate as 2 , weak as 1 , and negative as 0 . Each intensity score was then summed with the score of the percentage of cells that were stained, with $>50 \%$ of the cells as $2,<50 \%$ of the cells as 1 , and none as 0 . Oneway ANOVA was used to analyze the population scores between the two stages of cancer progression (bone vs benign, well-differentiated, or poorly-differentiated, or well-differentiated vs benign). The Gleason grade of the tumors and the quantification of the staining were determined by a pathologist, Dr Peizhen $\mathrm{Hu}$.

\section{Construction of RANKL and c-Met promoter-luciferase reporter plasmid and deletion mutants}

The $2.5 \mathrm{~kb}$ human RANKL promoter was amplified from the human BAC clone RP11-86N24 using primers 5'-GTGCACAGAATTCTTCAGGGGGCAAGTC-3' (forward) and 5'-GCGAAGCTTCATGGCGCTCGGCCCTCTCG-3' (reverse). The amplified fragment was subsequently subcloned into a firefly luciferase expression vector pGL3-basic (Promega). The authenticity of the $2.5 \mathrm{~kb}$ RANKL promoter region was confirmed by DNA sequencing. A series of deletion mutants of the RANKL promoter were generated from the $2.5 \mathrm{~kb}$ RANKL promoter using a QuikChange II XL SiteDirected Mutagenesis Kit following the manufacturer's instructions (Stratagene, Santa Clara, CA, USA). Human c-Met promoter-luciferase and its deletion constructs were provided by Dr Y Liu (Department of Pathology, University of Pittsburgh). Additional deletion constructs were also generated by the above protocol. Human AR promoter $(6 \mathrm{~kb})$ was provided by Dr Donald Tindall (Mayo Clinic).

\section{Transient transfection and luciferase reporter assay}

RANKL, c-Met, and AR promoters and deletion mutants plus $\beta$-galactosidase plasmid (for transfection efficiency control) were transiently transfected into PCa cells using
Lipofectamine 2000 (Invitrogen) for $48 \mathrm{~h}$. After $48 \mathrm{~h}$, the transfected cells were serum-starved for $24 \mathrm{~h}$ before treatment with RANKL, OPG, or RANKL plus OPG for another 48 h. For c-Myc inhibition, LNCaP cells were pretreated with $40 \mu \mathrm{M}$ 10058-F4 c-Myc inhibitor for $4 \mathrm{~h}$ before treatment with RANKL. The luciferase promoter assay was conducted as described previously (Huang et al. 2010).

\section{Flow cytometry}

Fluorescence-activated cell sorting (FACS) analyses were conducted as described previously (Sheridan et al. 2006). Stained cells were analyzed by BD Accuri C6 flow cytometer (BD, Franklin Lakes, NJ, USA) and results further analyzed using FlowJo Software (Ashland, OR, USA).

\section{Microarray analysis}

Human U133plus2.0 array hybridizations were performed by the UCLA Clinical Microarray Core following the standard Affymetrix GeneChip Expression Analysis protocol. The acquisition of array images was undertaken using the Affymetrix GeneChip Command Console 1.1 (AGCC). The microarray data are publically available (GEO GSE48432).

\section{Computational analyses of global gene expression profile}

The guanine cytosine robust multi-array analysis (GCMRA) method was applied to adjust the background signal. Probe intensities were normalized using the quantile normalization procedure ( $\mathrm{Wu}$ et al. 2004). Integrated hypothesis testing included i) two independent tests, the $T$-test and the $\log 2$ median ratio test; ii) for each test, an empirical distribution of the null hypothesis that the means of the genes are not different was estimated by random permutations of the samples; iii) for each gene, the false discovery rate (FDR) was computed by a two-tailed test using the empirical distributions by Storey's method (Storey \& Tibshirani 2003); and iv) the two sets of FDRs from the individual tests were combined to compute the overall FDR using Stouffer's method (Hwang et al. 2005). Finally, differentially expressed genes (DEGs) were selected for i) FDR $<0.05$ and ii) absolute expression changes larger than twofold. From 3345 DEGs (FDR $<0.05$, log2 fold change $\geq 1$ ), we found that 1644 genes were upregulated and 1701 genes were significantly downregulated. A functional enrichment analysis of the list of up- and downregulated genes using the Database for Annotation, Visualization and Integrated Discovery (DAVID) Software (Bethesda, MD, USA) (Huang da et al. 2009) identified cellular processes enriched by the DEGs.

Published by Bioscientifica Ltd 
Probability of significance was transformed into enrichment score, which is $-\log _{10}$ (enrichment $P$ value).

\section{MR analysis for identification of key TFs}

To identify key TFs, we first collected about 780000 items of TF target interaction data for 391 TFs in the public databases including TRED (Zhao et al. 2005), EEDB (Severin et al. 2009), mSigDB (Subramanian et al. 2005), Amadeus (Linhart et al. 2008), OregAnno (Griffith et al. 2008), PAZAR (PortalesCasamar et al. 2007), and ChEA (Lachmann et al. 2010). We used Fisher's exact test (FET; Carro et al. 2010) to compute the significance of overlap between the TF-targets and DEGs of interest including RANK receptor downstream signaling, TF modules, EMT, stemness, and neuroendocrine differentiation. Then we selected eight TFs whose targets were significantly enriched by the upregulated DEGs $(P<0.01$ in FET).

\section{Identification of disease phenotypes}

Upregulated genes in RANKL-overexpressed cells compared with control cells were used to identify associated human disease phenotypes using g:Profiler (Reimand et al. 2011), providing gene annotations from the HPO, a standardized vocabulary of phenotypic abnormalities encountered in human disease. Finally, we selected a list of disease/disease phenotype associations enriched by the 1644 upregulated genes with $P<0.05$.

\section{Statistical analysis}

Differences between groups were analyzed using Student's $t$-test (two groups), one-way ANOVA (three or more groups), two-way ANOVA (two or more factors), or FET as appropriate. Where multiple groups were compared using ANOVA, a post hoc Tukey's or Dunnett's method was used to enable multiple comparisons between groups. Data that were not normally distributed were log-transformed before statistical tests were perfomed. A $P$ value $<0.05$ was considered statistically significant. All statistical analysis was performed using R v2.15.1.

\section{Results}

RANKL expression increases with human PCa progression and is capable of driving non-metastatic PCa cells to colonize bone and soft tissues in mice

RANKL is prevalently expressed in human PCa specimens, with increased expression in higher grade and metastatic tumors compared with benign and low-grade PCa (Fig. 1A). We previously demonstrated that RANKL expression was significantly correlated with the overall survival of PCa patients (Hu et al. 2013). Moreover, RANKL expression correlates with the ability of PCa to metastasize to bone. $\mathrm{ARCaP}_{\mathrm{M}}$ and $\mathrm{LN}^{\mathrm{RANKL}}$ cells expressed respectively more intrinsic or transfected RANKL than their parental $\mathrm{ARCaP}_{\mathrm{E}}$ and $\mathrm{LN}^{\mathrm{Neo}}$ cells as determined by IHC (Fig. 1B). ARCaP $\mathrm{M}$ cells were observed to express high levels of endogenous RANKL. Silencing of RANKL in $\mathrm{ARCaP}_{\mathrm{M}}$ cells resulted in attenuation of the cells' mesenchymal phenotype (Fig. 1C) and their migratory and invasive potential (Fig. 1D). Consistent with this result, silencing of RANK, the cognate receptor for RANKL, abolished the cells' metastatic potential (Fig. 1E). Because androgen-responsive, non-metastatic LNCaP cells expressed low levels of RANKL, we tested whether stable, forced RANKL expression in $\mathrm{LNCaP}\left(\mathrm{LN}^{\mathrm{RANKL}}\right)$ cells promoted RANKL-RANK signaling and bone metastasis. Relative expression levels of RANKL, RANK, and OPG in $\mathrm{LN}^{\mathrm{RANKL}}$ and control neotransfected $\mathrm{LN}^{\mathrm{Neo}}$ cells, $\mathrm{ARCaP}_{\mathrm{E}}$, and $\mathrm{ARCaP}_{\mathrm{M}}$ are shown in Fig. 2A. To test the possibility that RANKL expression in PCa cells confers bone metastasis in mice, $1 \times 10^{6} \mathrm{LN}^{\mathrm{RANKL}-\mathrm{Luc}}$ or control $\mathrm{LN}^{\mathrm{Neo}-\mathrm{Luc}}$ cells were injected intracardially into mice. In marked contrast to the indolent $\mathrm{LN}^{\mathrm{Neo}-\mathrm{Luc}}(0 / 15)$, LN $^{\text {RANKL-Luc }}$ cells metastasized primarily to bone (20/20) and, less uniformly, to lymph node (18/20), lung (8/20), and adrenal gland $(17 / 20)$ as evaluated by bioluminescence (Fig. 2B). The predominant metastatic lesions in mouse skeletons were osteolytic, with a minor osteoblastic component as evaluated by $\mu \mathrm{CT}$ (Fig. 2C). The presence of tumor cells and the differentiation of pre-osteoclasts to mature osteoclasts in PCa bone lesions was validated by $\mathrm{H} / \mathrm{E}$ and positive TRAP staining (Fig. 2D). Because $\mathrm{LN}^{\mathrm{RANKL}}$ cells produced secreted RANKL $(\sim 3 \mathrm{ng} / \mathrm{ml}$; data not shown), we tested the effect of i.p. injection of recombinant soluble RANKL (sRANKL, $50 \mu \mathrm{g} / \mathrm{kg}$, twice a week) on bone colonization of intratibially inoculated, non-metastatic $\mathrm{LN}^{\text {Neo-RFP-Luc }}$ cells. Mice that had received injections of RANKL exhibited bone metastases while no tumors formed in the skeleton in the animals that received injections of vehicle only (Fig. 2E). sRANKL was shown previously to induce bone turnover/resorption in rat bone; however, spontaneous tumor formation in response to this cytokine does not occur (McHugh et al. 2003).

\section{RANKL-RANK signaling alters an expansive gene expression program and controls c-Met and AR gene expression}

We conducted a global analysis of RANKL-perturbed genes by transcriptome profiling of $\mathrm{LN}^{\mathrm{RANKL}}$ and $\mathrm{LN}^{\mathrm{Neo}}$ cells.

Published by Bioscientifica Ltd. 
This analysis showed that increased expression of RANKL promoted the expression of i) development-related genes regulating stem cells, neuronal differentiation, and morphogenesis; ii) genes controlling cell migration, angiogenesis, chemotaxis, and EMT; iii) genes associated with increased cell proliferation and decreased apoptosis; and iv) genes controlling bone development, bone morphogenesis, ossification, and tissue renewal (Supplementary Fig. 1, see section on supplementary data given at the end of this article). Increased RANKL expression significantly activated a number of cell signaling networks downstream from RANK that support cell growth, survival, and cell cycle
A

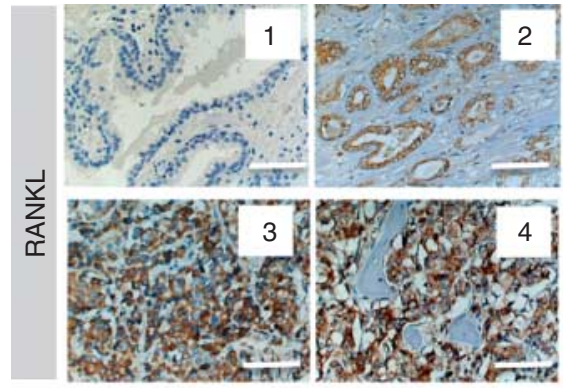

B
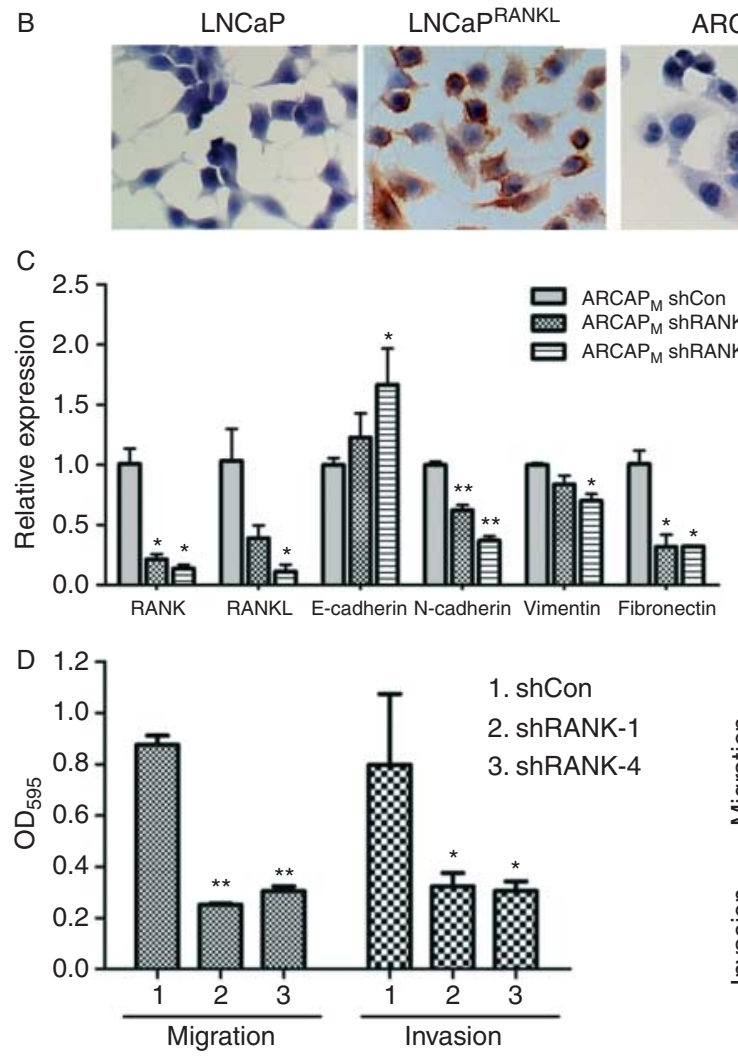
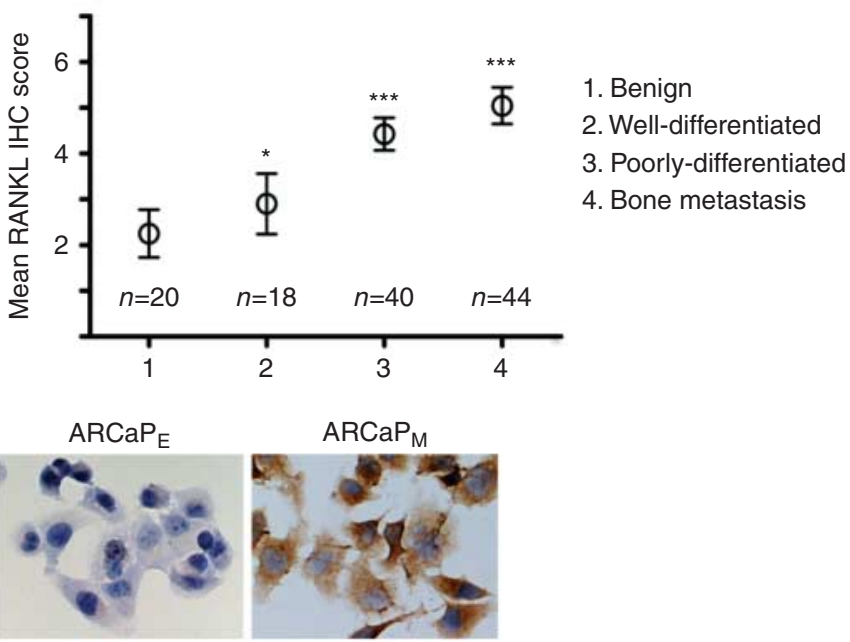
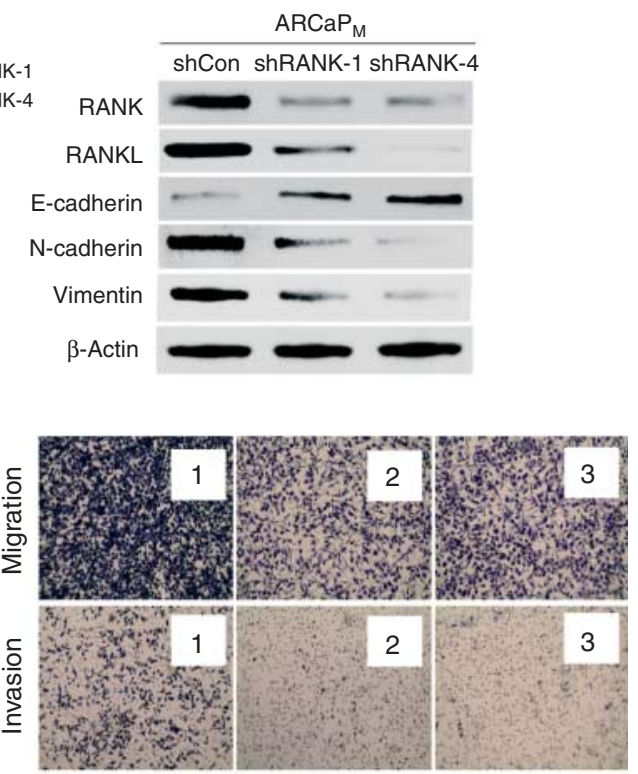

$\mathrm{E}$

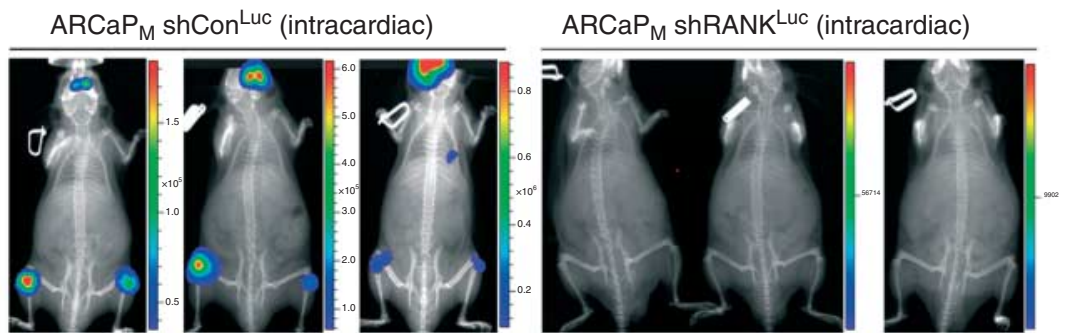



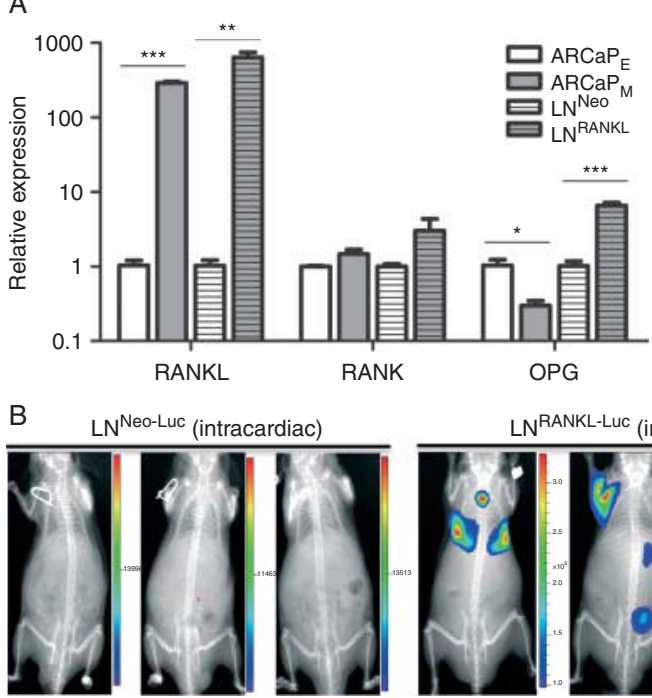

C

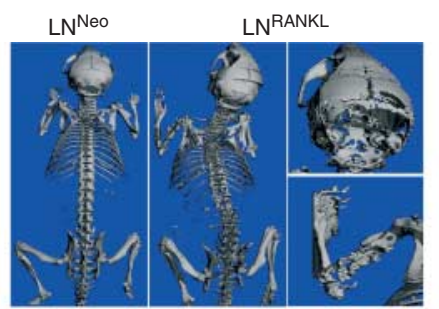

D

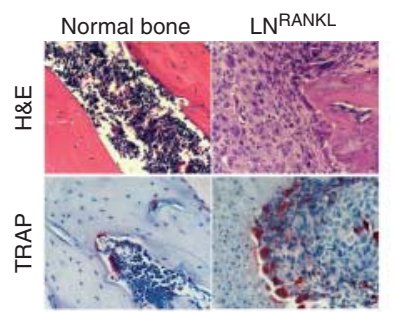

E

LN ${ }^{\text {RANKL-Luc (intracardiac) }}$

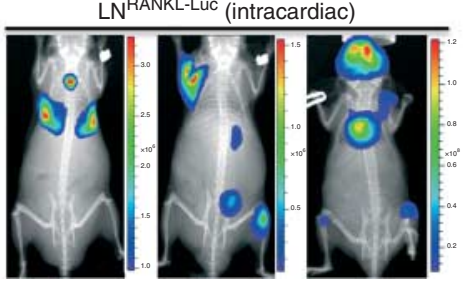

LN Neo-RFP-Luc (intraosseus)

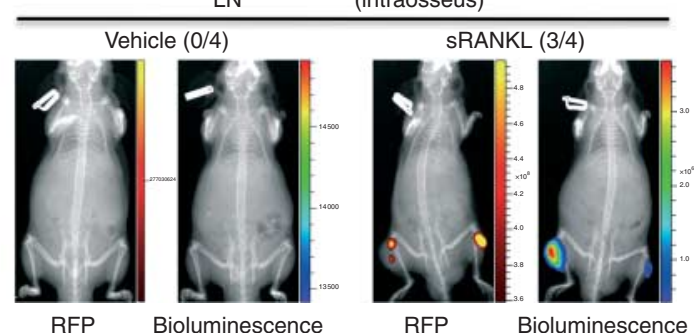

\section{Figure 2}

RANKL overexpression in PCa cells confers increased lethal and osteolytic bone metastasis in nude mice. (A) RANKL, RANK, and OPG expression was assessed in human PCa $A R C a P_{E}$ and $\mathrm{ARCaP}_{\mathrm{M}}$ EMT cell model and human $\mathrm{LN}^{\mathrm{Neo}}$ and LN ${ }^{\mathrm{RANKL}}$ cells by qRT-PCR $\left({ }^{*} P<0.05\right.$; ${ }^{*} P<0.01$; and $\left.* * * P<0.001\right)$. (B) Representative bioluminescent images showed that luciferase-tagged $\mathrm{LN}^{\mathrm{RANKL}}$ cells, but not luciferase-tagged $\mathrm{LN}^{\mathrm{Neo}}$ control cells, induced bone

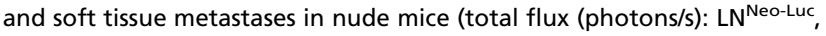
$1.88 \times 10^{4}, 1.53 \times 10^{4}$, and $1.05 \times 10^{4} ;$ LN $^{\text {RANKL-Luc }}, 1.92 \times 10^{7}, 3.79 \times 10^{6}$, and $4.14 \times 10^{8}$ ). (C) Representative 3D $\mu C T$ images of mice bearing $L^{N e o}$ and $\mathrm{LN}^{\mathrm{RANKL}}$ cells showed that RANKL overexpression induced predominantly

progression, as well as TFs controlling growth factor and growth factor receptor signaling, EMT, and stem cell and neuroendocrine cell phenotypes (Fig. 3A). Key TFs in the RANKL-perturbed cell signaling network were identified by MR analysis using a computational approach described in the Supplementary Materials and Methods. We identified eight key TFs governing regulation of the 1644 RANKLperturbed upregulated genes based on MR analysis $(P<0.01$; Fig. 3B). The targets of these eight key TFs accounted for $87 \%$ of genes upregulated in response to RANKL. Although expression of four of the key TFs, SOX2, MYC, POU5F1, osteolytic lesions in mouse skeleton. (D) Representative $\mathrm{H} / \mathrm{E}$ and positive TRAP staining in tumors in mouse bone induced by $L N^{\text {RANKL }}$ cells. (E) Representative red fluorescent or bioluminescent images showed sRANKL $(50 \mu \mathrm{g} / \mathrm{kg}$ i.p. twice a week, 2 weeks after intraosseous inoculation of $1 \times 10^{6}$ PCa cells) induced tumor growth in mouse tibia inoculated with $\mathrm{LN}^{\text {Neo-RFP-Luc }}$ cells $(n=4)$. No tumor was observed in vehicle-treated mice (average total radiant efficiency of RFP $\left((\mathrm{p} / \mathrm{s}) /\left(\mu \mathrm{W} / \mathrm{cm}^{2}\right)\right)$ or total flux $(\mathrm{p} / \mathrm{s})$ of bioluminescence: vehicle, $3.68 \times 10^{8}$ (RFP) and $8.96 \times 10^{3}$ (bioluminescence); sRANKL, $2.34 \times 10^{9}$ (RFP) and $8.63 \times 10^{6}$ (bioluminescence)).

and RELA, was not significantly different in the two cell lines, the number of their regulatory targets in the RANKLperturbed cell signaling network (Fig. 3A) is highly significant according to MR analysis (Fig. 3B). Other key TFs also showed significant target occupation in RANKLoverexpressing cells compared with $\mathrm{LN}^{\mathrm{Neo}}$ cells. RANKL was observed to activate a large number of genes and pathways closely associated with bone development and morphogenesis (Fig. 3C).

$\mathrm{LN}^{\mathrm{RANKL}}$ cells expressed increased endogenous RANKL and c-Met and decreased AR mRNA and protein (Fig. 4A).

\section{Figure 1}

RANKL expression correlates with PCa progression in clinical specimens and cell models. (A) RANKL expression was negative or low in benign tumors but positive in well-differentiated and poorly-differentiated human primary and metastatic specimens. Increased RANKL expression correlated with human PCa progression from benign to bone metastasis. Relative scores of RANKL IHC staining in benign $(n=20)$, well-differentiated $(n=18)$, poorly-differentiated $(n=40)$, and bone metastatic prostate tumors $(n=44)$ are presented with statistical significance compared to benign tumors (400× magnification; $* * * P \leq 0.001$; and $* P \leq 0.05)$. (B) RANKL expression was shown to be negative or low in $\mathrm{LN}^{\mathrm{Neo}}$ and $A R C a P_{E}$ cells but high in $\mathrm{LN}^{\mathrm{RANKL}}$ and $\mathrm{ARCaP} \mathrm{M}_{\mathrm{M}}$ cells by immunohistochemical (IHC) staining
(400 $\times$ magnification). (C) $\mathrm{ARCaP}_{\mathrm{M}}$ cells with RANK knockdown demonstrated decreased mesenchymal marker expression but increased epithelial marker expression detected by qRT-PCR and western blot analyses ( ${ }^{*} P<0.05$; and $\left.{ }^{*} P<0.01\right)$. (D) RANK knockdown also decreased in vitro migration and invasion potential of $\mathrm{ARCaP}_{\mathrm{M}}$ cells with the representative images of the migrated/invaded cells on the other side of the trans-wells, indicating a reversion of EMT to mesenchymal-to-epithelial transition $\left({ }^{*} P<0.05\right.$; and $\left.{ }^{* *} P<0.01\right)$. (E) RANK knockdown in $\mathrm{ARCaP}_{\mathrm{M}}$ cells failed to establish any metastasis in athymic nude mice $(n=10$; average total flux (photons/s): ARCaP $_{\mathrm{M}}$ shCon ${ }^{\text {Luc }}$ (intracardiac), $2.54 \times 10^{5}, 8.71 \times 10^{5}$, and $2.01 \times 10^{5} ;$ ARCaP $_{M}$ shRANK $^{\text {Luc }}$ (intracardiac), $3.45 \times 10^{4}$ and $4.86 \times 10^{3}$ ).

Published by Bioscientifica Ltd. 
A

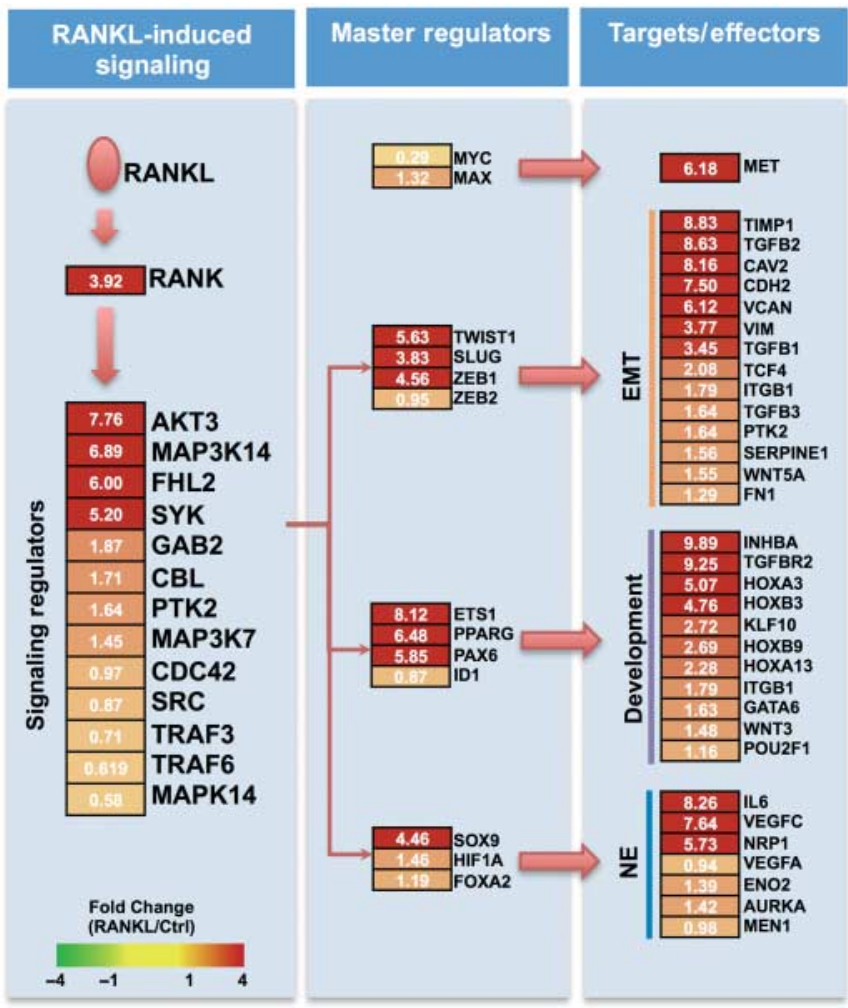

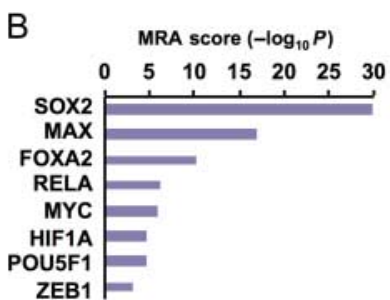

C Enrichment score $\left(-\log _{10} P\right)$

$\begin{array}{lllllll}0 & 1 & 2 & 3 & 4 & 5\end{array}$

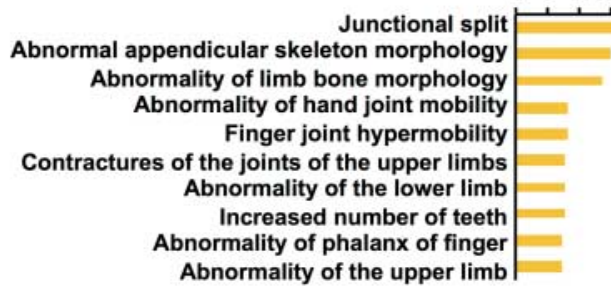

\section{Figure 3}

RANKL-perturbed network and master regulators. (A) RANKL pathway with upregulated genes in RANKL-overexpressing cells. RANKL-perturbed signaling and key TFs are shown. Node colors represent fold change in RANKLoverexpressing cells compared with controls. EMT, epithelial-to-mesenchymal transition; Development, development-related genes including differentiation

c-Met activation, as indicated by increased phosphorylation (at tyrosine 1230/1234/1235 sites), was also increased in $\mathrm{LN}^{\mathrm{RANKL}}$ cells. Expression of RANKL, c-Met, and activated c-Met was attenuated by a RANKL decoy receptor, OPG, or an anti-RANKL antibody, denosumab (Fig. 4B). These findings indicate that RANK-RANKL signaling significantly alters an oncogenic signaling program. To approach the mechanism underlying these changes, we used RANKL-, c-Met-, and AR-promoter luciferase constructs to identify cis-elements and TFs that may control them. Both the RANKL- and c-Met promoter regions contain E boxes (CACGTG) at -1384 or $-1250 \mathrm{bp}$ respectively. These are consensus regions for $\mathrm{c}-\mathrm{Myc} / \mathrm{Max}$ binding (Fig. 4D and E). Upregulation of RANKL and c-Met expression by enhanced RANK-RANKL signaling was mediated through direct interaction of the c-Myc/ Max heterodimer to the E-box region within RANKL and c-Met promoters as assessed by mutation (Fig. 4D and E), chromatin immunoprecipitation (ChIP) (Supplementary Fig. 2A and C, see section on supplementary data and stemness; NE, neuroendocrine differentiation. (B) Independent analysis to identify master regulators predicted by master regulator analysis (MRA) score, which is $-\log _{10}$ transformed value of significance ( $P$ values). (C) Bioinformatics analysis using g:Profiler revealed that bone-related diseases are representative features of RANKL-overexpressing LNCaP cells.

given at the end of this article), and electrophoretic mobility shift assay (EMSA) (Supplementary Fig. 2B). Deletion of the cis-elements required for c-Myc/Max interaction dramatically decreased promoter-luciferase activities in $\mathrm{LN}^{\mathrm{RANKL}}$ cells (Fig. 4D and E). Similar downregulation of promoter activity was observed when LN $^{\text {RANKL }}$ cells were treated pharmacologically with 10058-F4 $(40 \mu \mathrm{M})$, which interferes with c-Myc function by preventing its dimerization with Max, or by lentiviral c-Myc shRNA knockdown, which greatly depressed c-Myc expression and hindered c-Myc/Max binding to its ciselement. The feed-forward action of RANKL-RANK signaling in promoting RANKL and c-Met via increased c-Myc/Max TF protein expression found in $\mathrm{LN}^{\mathrm{RANKL}}$ was also observed in LNCaP cells treated with exogenous recombinant RANKL (Fig. 4C). Previously, Nadiminty et al. (2012) reported that AR transcription is regulated by miRNA-let7c via c-Myc. Interestingly, we observed coordinated suppression of AR expression, mediated through c-Myc/Max heterodimer and/or AP4 homodimer, and AP4

Published by Bioscientifica Ltd. 

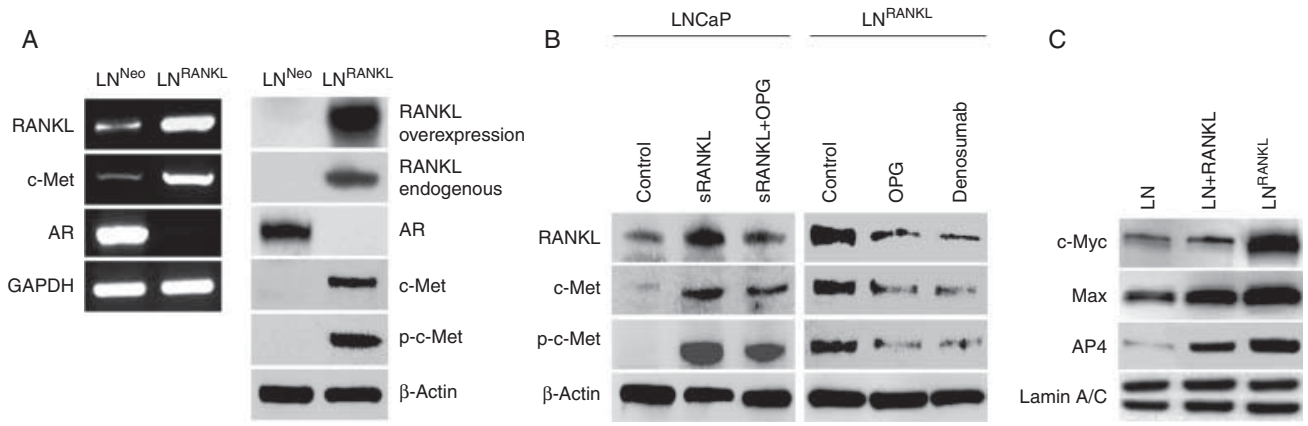

D

Human RANKL promoter constructs Luciferase reporter activity (RLU, $\left.\times 10^{5}\right)$
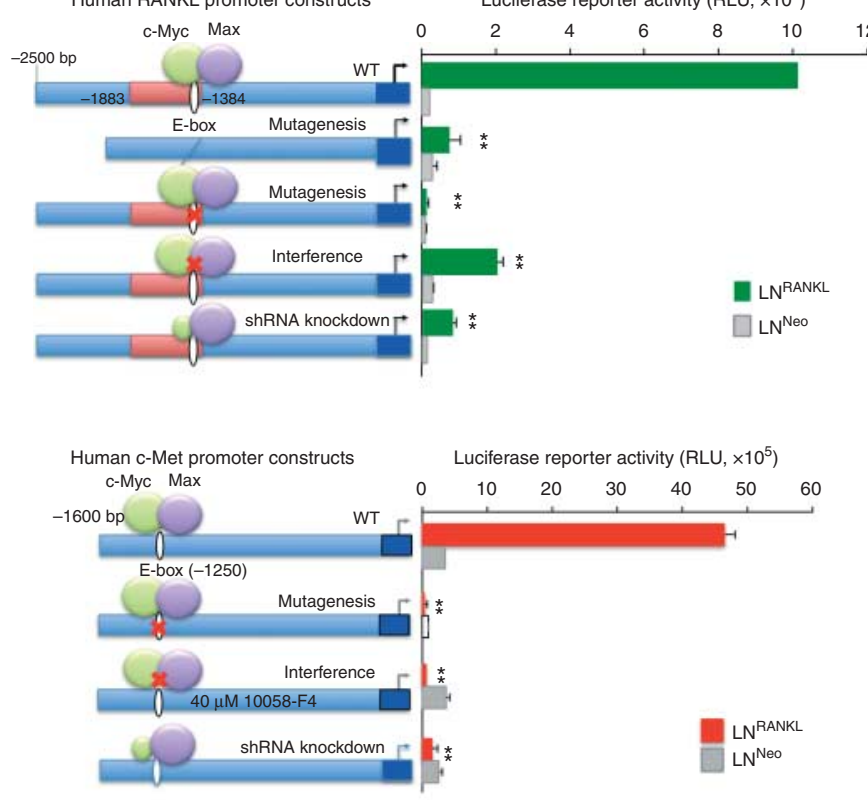

F

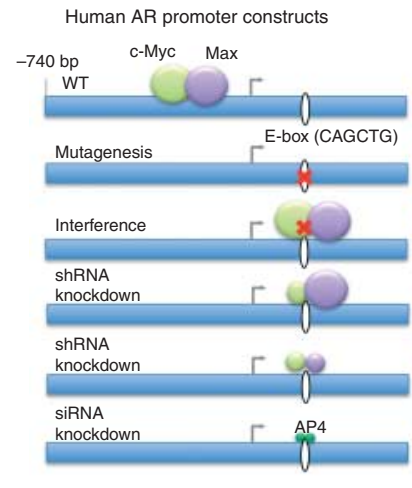

Luciferase reporter activity (RLU, $\left.\times 10^{5}\right)$

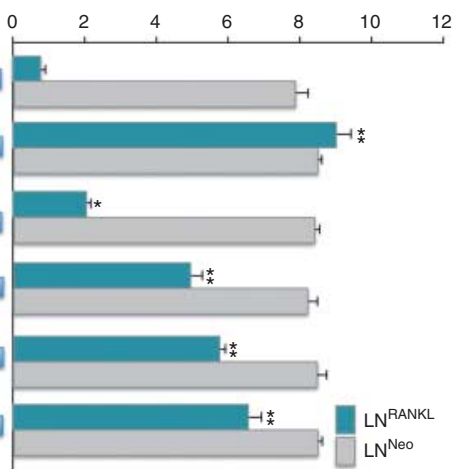

Figure 4

RANKL induces expression of RANKL and c-Met but suppresses AR expression/activation through c-Myc/Max and AP4 transcription factors in the LNCaP cell background. (A) RANKL overexpression upregulates endogenous RANKL and c-Met expression and c-Met phosphorylation but suppresses AR expression. (B) Exogenous RANKL treatment or intrinsic RANKL expression induces endogenous RANKL expression, c-Met expression, and c-Met phosphorylation. Inductions are partly sensitive to OPG or anti-RANKL antibody (denosumab) treatments. (C) RANKL-RANK signaling increases the level of c-Myc and Max expression. Increased c-Myc and Max nuclear proteins were observed in LNCaP cells treated with RANKL

or in $\mathrm{LN}^{\mathrm{RANKL}}$ cells as evaluated by western blot analysis. Lamin A/C was used as internal control. (D) Activities of human RANKL, (E) C-Met, and (F) AR promoter-luciferase reporter constructs were compared between $\mathrm{LN}^{\mathrm{RANKL}}$ and $\mathrm{LN}^{\text {Neo }}$ cells. Site-directed mutagenesis was used to remove the E-box, the cis-element required for C-Myc/Max interaction. Complementary experiments confirmed the results by assaying promoter reporter activities under 10058-F4 $(40 \mu \mathrm{M})$ exposure, known to inhibit c-Myc function by interference with its dimerization with Max, and by shRNA knockdown of the c-Myc, Max, or AP4 to suppress C-Myc/Max or AP4 binding to its E-box cis-element $(* P<0.05 ; * * P<0.01$; and $* * * P<0.001)$.

Published by Bioscientifica Ltd. 
has been shown to be a conserved and direct target gene of c-Myc (Cole \& McMahon 1999, Jung et al. 2008). The interaction site was identified at the E-box/AP4 binding site (CAGCTG) on the AR promoter region at $+374 \mathrm{bp}$. Deletion of the AP4 site significantly upregulated AR promoter activity in $\mathrm{LN}^{\mathrm{RANKL}}$ cells. Similarly, interference with c-Myc and Max dimerization with 10058-F4 or genetic ablation of c-Myc, c-Myc and Max, or AP4 using shRNA or siRNA also increased AR promoter activity in $\mathrm{LN}^{\text {RANKL }}$ cells (Fig. 4F). ChIP analysis further demonstrated direct interaction of c-Myc, Max, and AP4 with the AP4 site within the AR promoter (Supplementary Fig. 2D). AR expression at the RNA and protein level was restored by knocking down c-Myc, c-Myc and Max, or AP4 in LN ${ }^{\mathrm{RANKL}}$ cells (Supplementary Fig. 3, see section on supplementary data given at the end of this article).

\section{RANKL-RANK signaling promotes EMT and stem and neuroendocrine phenotypes}

Consistent with our previous report using ARCaP cells (Zhau et al. 2008), RANKL-RANK signaling also promoted the expression of EMT markers in LNCaP cells. Increased expression of RANKL induced the expression of mesenchymal features, including subtle morphological changes to a more spreading morphology (Supplementary Fig. 4A, see section on supplementary data given at the end of this article), mesenchymal gene expression profiles (increased $\mathrm{N}$-cadherin, and vimentin expression but decreased E-cadherin expression, Supplementary Fig. 4B), and more aggressive cell behaviors (increased cell motility, migration, invasion, and anchorage-independent growth, Supplementary Fig. 4C and D). LNCaP cell-derived RANKL or exogenously administered recombinant RANKL are biologically functional and induce pre-osteoclast maturation as measured by increased TRAP + staining, when co-cultured with mouse RAW264.7 pre-osteoclasts (Supplementary Fig. 5, see section on supplementary data given at the end of this article). This activity was attenuated by a RANKL decoy receptor, OPG.

RANKL-RANK signaling also promoted stem cell and neuroendocrine differentiation in LNCaP cells. Figure 5A shows increased expression of the stem cell markers CD44, CD133, SOX2, OCT3/4, CD49f, Lin28b, and Nanog. Figure $5 \mathrm{~B}$ shows elevated expression of the neuroendocrine markers FOXA2, SYP, and chromogranin A. Induced expression of stem cell and neuroendocrine markers was partly blocked by denosumab and OPG, indicating that the maintenance of these phenotypes requires continuous RANKL-RANK signaling (Fig. 5C and D). Consistent with higher intrinsic RANKL expressed by $\mathrm{ARCaP}_{\mathrm{M}}$ cells, we also observed that this cell line expressed higher levels of TFs that regulate EMT, stem, and neuroendocrine phenotypes (Supplementary Fig. 6, see section on supplementary data given at the end of this article). Together, these results are consistent with previous reports showing that cancer cells undergoing EMT expressed stem cell characteristics (Kong et al. 2011). The emergence of an neuroendocrine phenotype in the $\mathrm{LNCaP}$ as well as $\mathrm{ARCaP}_{\mathrm{M}}$ cell backgrounds in response to RANKL-RANK signaling has not been reported and is probably due to the activation of TFs such as FoxA2, SOX9, and HIF1 $\alpha$ that regulate the neuroendocrine phenotype of PCa cells (Qi et al. 2010).

\section{RANK, c-Met, and c-Myc/Max are required for bone colonization by $\mathrm{LN}^{\mathrm{RANKL}}$ cells}

RANKL-RANK signaling seems obligatory for bone colonization. LN $^{\text {RANKL }}$ cells with RANK knockdown (Fig. 6A) formed very small tumors in mice tibias, undetectable by NIR dye-based fluorescence imaging (Yang et al. 2010) but detectable by X-ray (Fig. 6B); moreover, the tumors were less osteolytic and much less bone resorptive compared with bone tumors derived from control shRNA-transduced LN ${ }^{\text {RANKL }}$ cells (Fig. 6C). Administration of sRANKL failed to induce bone tumor formation in mice bearing intratibially injected RANK-silenced $\mathrm{LN}^{\mathrm{RANKL}}$ cells (Fig. 6D). Knockdown of the RANK downstream target TFs, c-Myc/Max, or its effector/target, c-Met, completely abolished the ability of $\mathrm{LN}^{\mathrm{RANKL}}$ cells to form skeletal or soft tissue metastasis in mice (Fig. 6E). These results support the obligatory role of RANKL-RANK, c-Myc/Max, and c-Met signaling in cancer bone colonization.

\section{Metastatic $L N^{\text {RANKL }}$ cells transform neighboring non-metastatic $\mathrm{LN}^{\mathrm{Neo}}$ cells}

We tested the ability of $1 \times 10^{3} \mathrm{LN}^{\mathrm{RANKL}}$ cells combined with $1 \times 10^{6}$ non-metastatic $1 \times 10^{6} \mathrm{LN}^{\mathrm{Neo}}$ cells to form tumors in mouse skeleton after intratibial injection. While neither $\mathrm{LN}^{\mathrm{RANKL}}$ nor $\mathrm{LN}^{\mathrm{Neo}}$ cells when injected individually in these amounts form tumors during a 3-month observation period, tumors arose from the mixed cell populations in $<2$ months (Fig. 7A). A similar result was observed when $\mathrm{LN}^{\mathrm{RANKL}}$ cells were injected into the tibia and $\mathrm{LN}^{\mathrm{Neo}-\mathrm{RFP}}$ cells were injected by the intracardiac route (Fig. 7B). IHC analysis revealed that tumors were chimeras consisting of RFP-positive and -negative cells that abundantly expressed RANKL, c-Met, and p-c-Met (Fig. 7C), although parental $\mathrm{LN}^{\text {Neo-RFP }}$ cells expressed undetectable levels of RANKL, c-Met, and p-c-Met in culture.

Published by Bioscientifica Ltd. 
A
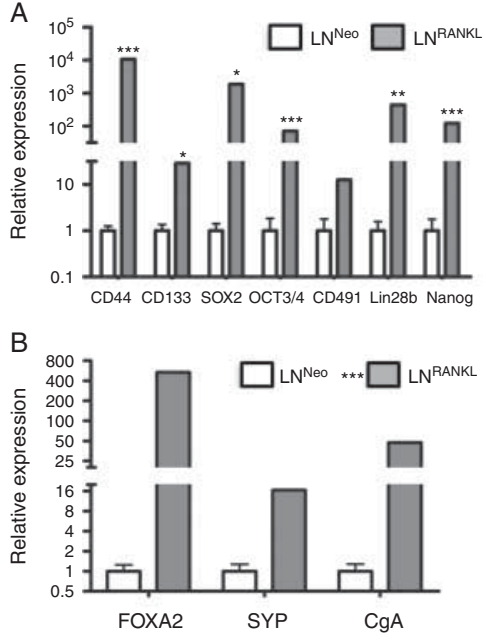

$\mathrm{D}$
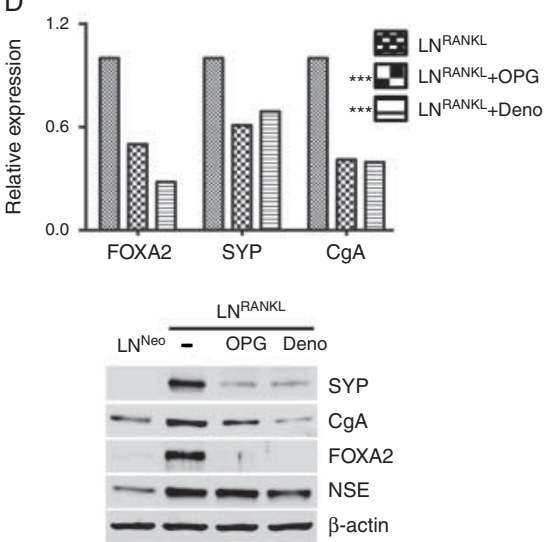

C
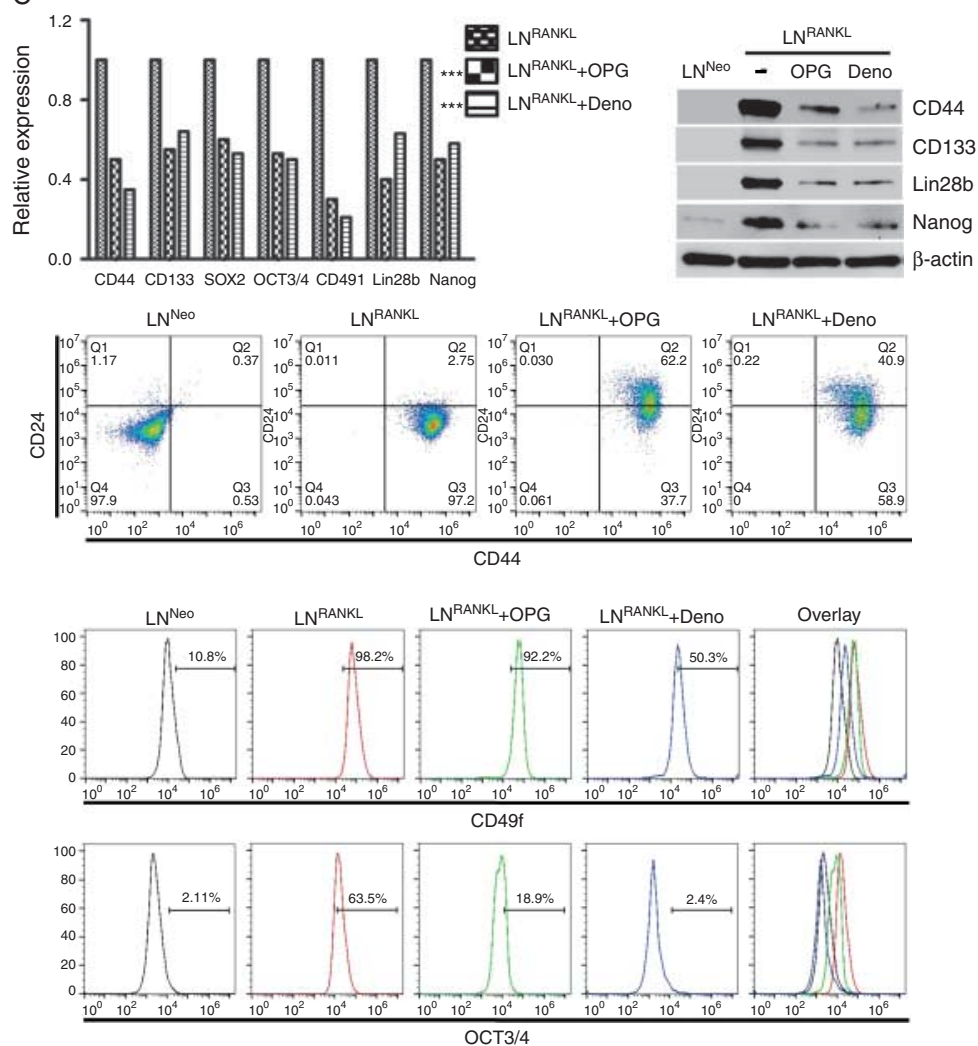

Figure 5

RANKL promotes stem cell and neuroendocrine properties of PCa cells. $L^{\text {RANKL }}$ cells have elevated gene expression of $(A)$ stem cell markers and (B) neuroendocrine markers confirmed by qRT-PCR. (C) Upregulation of stem cell markers by RANKL expression can be attenuated by OPG and denosumab treatments as analyzed by qRT-PCR, western blot, and flow cytometry. (D) OPG and denosumab also downregulate the expression of

We cloned LN ${ }^{\text {Neo-RFP }}$ cells from harvested chimeric tumors using the RFP marker and characterized the gene expression profiles of the cultured sublines. Figure 7D shows that tumorderived $\mathrm{LN}^{\mathrm{Neo}-\mathrm{RFP}}$ cells in culture exhibited patterns of gene expression resembling $\mathrm{LN}^{\mathrm{RANKL}}$ cells, patterns distinctly different from those of the parental $\mathrm{LN}^{\mathrm{Neo}-\mathrm{RFP}}$ cells. We subsequently labeled both parental and tumor-derived $\mathrm{LN}^{\mathrm{Neo}-\mathrm{RFP}}$ cells with luciferase, and when injected intratibially, only the tumor-derived $\mathrm{LN}^{\text {Neo-RFP-Luc }}$ cells but not the parental $\mathrm{LN}^{\text {Neo-RFP-Luc }}$ cells colonized the mouse skeleton (Fig. 7E). These results, in aggregate, indicate that $\mathrm{LN}^{\mathrm{RANKL}}$ cells are able to transform or reprogram neighboring bystander $\mathrm{LN}^{\mathrm{Neo}-\mathrm{RFP}}$ cells to generate tumors in bone.

In summary, these experiments demonstrate that a RANK-mediated signaling network can drive PCa tumor neuroendocrine markers in LN ${ }^{\text {RANKL }}$ cells, confirmed by both qRT-PCR and western blot analyses. (B, C and D) Statistical significance of differences between the treatment groups and the control group ( $\mathrm{LN}^{\mathrm{RANKL}}$ ) were calculated based on a global comparison for the set of genes. $* P<0.05$, $* * P<0.01$, and $* * * P<0.001$.

growth in the mouse skeleton. This mechanism involves a feed-forward process in which RANKL and c-Met are induced, and AR is downregulated, as well as a transcriptional network involving $\mathrm{c}-\mathrm{Myc} / \mathrm{Max}$ as an essential node. In this model system, downregulation of RANK, c-Myc/Max, or c-Met expression abolished the bonehoming potential in mice. RANKL-expressing PCa cells were also shown to exhibit transforming potential by altering the gene expression of neighboring bystander cells and coopting them to participate in bone colonization.

\section{Discussion}

Hormone-refractory, bone metastatic human prostate and breast cancers are typically lethal; however, little is known

Published by Bioscientifica Ltd. 
A

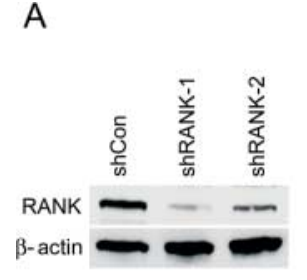

B

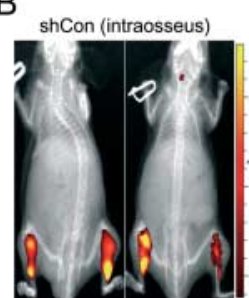

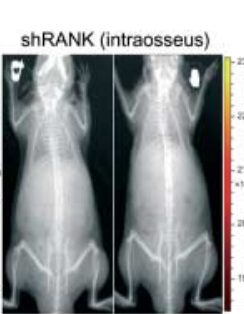

C

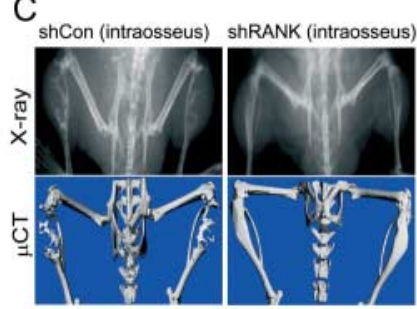

.

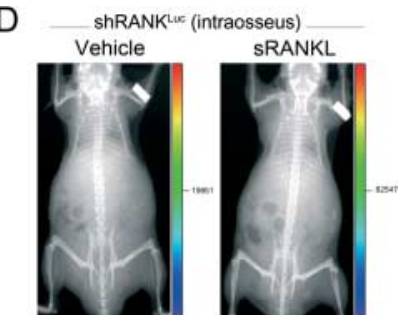

$\mathrm{E}$
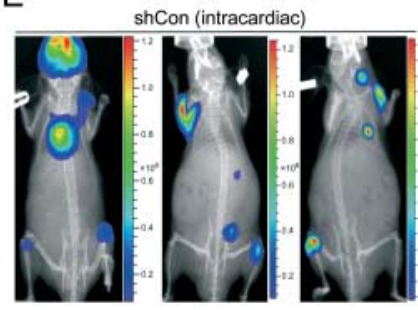

shRANK (intracardiac)
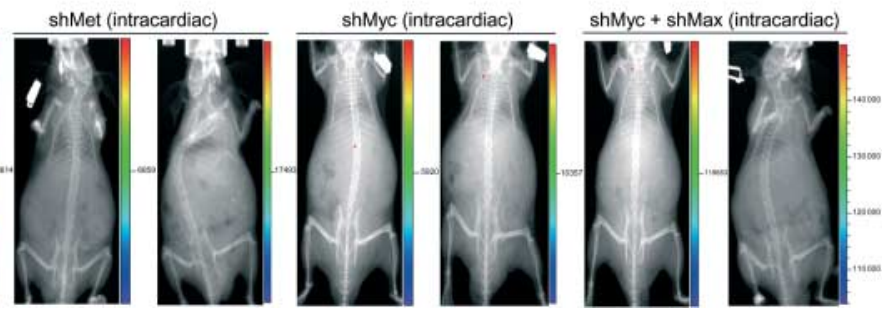

\section{Figure 6}

Abrogation of RANK or its downstream target transcription factors, c-Myc/Max, or its effector/target, c-Met abolishes the metastatic potential of LN $^{\text {RANKL }}$ cells. (A) Partial RANK knockdown in LN ${ }^{\text {RANKL }}$ cells was confirmed by western blot analysis. (B) Representative NIR fluorescent images showed that RANK-knocked-down LN ${ }^{\text {RANKL }}$ cells $(n=10)$ form no or very small tumors undetectable by NIR fluorescent imaging, but $\mathrm{LN}^{\mathrm{RANKL}}$ cells transduced with control shRNA (shCon) $(n=10)$ form obvious intratibial tumors (average total radiant efficiency of NIR $\left((\mathrm{p} / \mathrm{s}) /\left(\mu \mathrm{W} / \mathrm{cm}^{2}\right)\right)$ : shCon (intraosseus), $4.86 \times 10^{10}$ and $3.37 \times 10^{10}$; shRANK (intraosseus), $2.63 \times 10^{5}$ and $3.84 \times 10^{5}$ ). (C) X-ray and $\mu \mathrm{CT}$ scans showed that $L^{R A N K L}$ cells induced osteolytic lesions in mouse tibia, unlike RANK-knocked-down LN ${ }^{\text {RANKL }}$ cells where mouse tibia were intact with minimal detectable bone lesions. (D) Representative in vivo bioluminescent images further demonstrated that administration of recombinant SRANKL
$(50 \mu \mathrm{g} / \mathrm{kg}$ s.c. twice a week, 2 weeks after intraosseous inoculation of test cell line) fails to induce intratibial tumor formation of luciferase-tagged RANKknocked down LN ${ }^{\text {RANKL }}$ cells in mice $(n=10)$ (total flux (photons/s): shRANK-1 (intraosseus) vehicle, $2.53 \times 10^{3}$ and shRANK-1 (intraosseus) + sRANKL, $1.80 \times$ $10^{4}$ ). (E) Representative in vivo bioluminescent images further demonstrated that luciferase-tagged $\mathrm{LN}^{\mathrm{RANKL}}$ shCon cells, but not luciferase-tagged $\mathrm{LN}^{\text {RANKL }}$ cells with RANK $(n=10)$, c-Met $(n=10)$, c-Myc $(n=8)$, or c-Myc/Max $(n=8)$ knockdown, induce bone and soft tissue metastases after intracardiac injection (average total flux (photons/s): shCon (intracardiac), $4.60 \times 10^{8}$, $9.71 \times 10^{6}$, and $4.01 \times 10^{7} ;$ shRANK (intracardiac), $4.27 \times 10^{3}$ and $6.13 \times 10^{3}$; shMet (intracardiac), $4.52 \times 10^{3}$ and $2.25 \times 10^{4}$; shMyc (intracardiac), $8.51 \times 10^{3}$ and $1.83 \times 10^{4}$; and shMyc+shMax (intracardiac), $8.65 \times 10^{4}$ and $1.64 \times 10^{5}$ ).

common TF complexes, c-Myc/Max and AP4 (Fig. 4). ii) PCa bone colonization can be initiated by a small number of RANKL-expressing bone-colonizing metastasisinitiating cells that can recruit non-metastatic bystander cells to participate (Fig. 7A and B). iii) This recruitment of bystander cells involves feed-forward signal amplification, involving increased expression of RANKL, RANK, and c-Met (Fig. 7C and D). We suggest that the continued maintenance of RANK signaling output in the recruited bystander cells could be responsible for their tumorigenicity, increasing cancer cell growth, survival, and angiogenesis by activating p-c-Met and promoting EMT, stem cell, and neuroendocrine cell differentiation (Fig. 5).

Response to tumor-derived RANKL or exposure to recombinant RANKL protein, $\mathrm{LN}^{\mathrm{RANKL}}$, or $\mathrm{LN}^{\mathrm{Neo}} / \mathrm{LN}^{\mathrm{RFP}}$ cells in the bone microenvironment may establish a premetastatic niche through three potential mechanisms: i) interaction with cancer cells to amplify downstream targets and effectors through upregulation of a host of MR TFs, such as c-Myc/Max, FoxA2, Sox2, Sox9, Oct4, NF-кB RelA, HIF1 $\alpha$, and Zeb1, that promote growth, survival, angiogenesis, EMT and stem and neuroendocrine-cell http://erc.endocrinology-journals.org DOI: 10.1530/ERC-13-0548
(C) 2014 The authors Printed in Great Britain
Published by Bioscientifica Ltd 
A

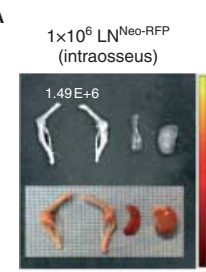

B

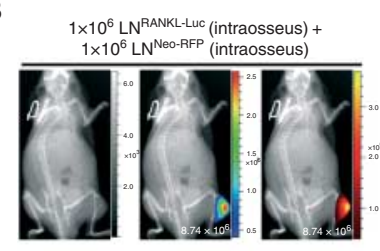

$1 \times 10^{3} \mathrm{LN}^{\text {RANKL }}$
$+1 \times 10^{6} \mathrm{LN}^{\text {Neo-RFP }}$ (intraosseus)

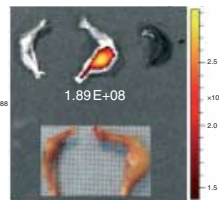

C

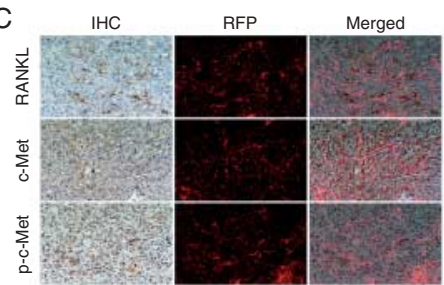

$+1 \times 10^{6} \mathrm{LN}^{\text {Neo-RFP }}$ (intraosseus)
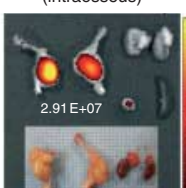

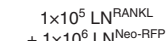
(intraosseus)
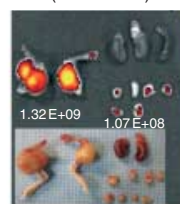

t)
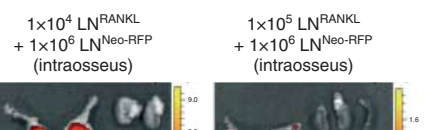

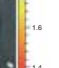

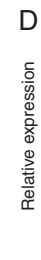

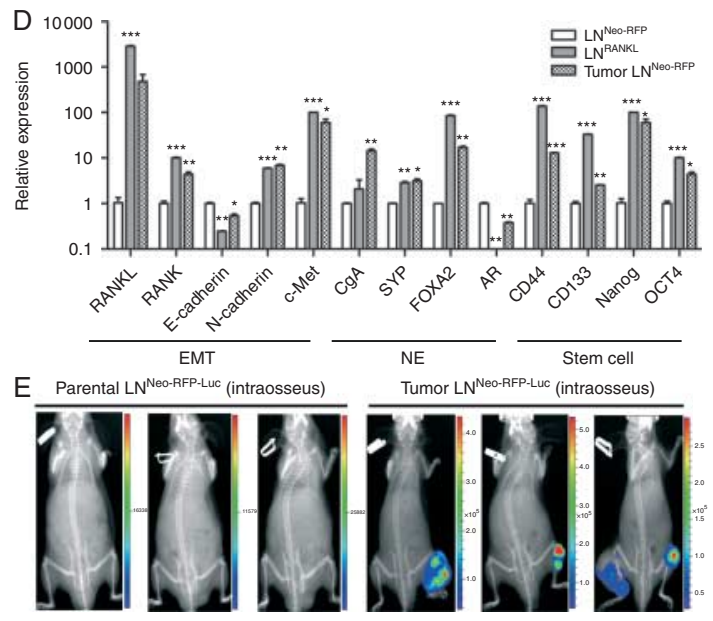

\section{Figure 7}

Metastatic $L N^{\text {RANKL }}$ cells can transform neighboring non-metastatic $L^{N e o}$ cells to undergo EMT, express neuroendocrine (NE) and stem cell biomarkers, and form tumors in mouse skeleton. (A) A small population of $L N^{\text {RANKL }}$ cells was capable of recruiting non-metastatic LN $^{\text {Neo-RFP }}$ cells, which were incapable of forming tumors by themselves, to participate in bone colonization in mice. One thousand, ten thousand, and one hundred thousand LN ${ }^{\text {RANKL }}$ cells were co-inoculated with one million LN ${ }^{\text {Neo-RFP }}$ cells in both tibia of nude mice. Tibial tumors and tumors disseminated from bone to soft tissues were harvested and subjected to fluorescent imaging to detect the red fluorescent signal from non-metastatic LN ${ }^{\text {Neo-RFP }}$ cells using the Xenogen imaging system at an excitation of $535 \mathrm{~nm}$ and emission of $620 \mathrm{~nm}$. Spleens were also harvested and used as negative controls. Total radiant efficiency $\left((\mathrm{p} / \mathrm{s}) /\left(\mu \mathrm{W} / \mathrm{cm}^{2}\right)\right)$ of the RFP in tumors was labeled in white in the corresponding tumors. (B) Representative in vivo bioluminescent and red fluorescent images were also demonstrated with mice bearing intratibial

phenotypes that promote cancer cell growth in bone (Fig. 3). ii) The effects of RANKL-expressing cells on bystander cells appear permanent, based on our ex vivo culture and profiling of RFP-labeled cells derived from bone metastases. These results support our previous observation that human PCa cells inoculated into immunodeficient mice recruited bystander cells, which underwent genetic modification, as exhibited by their cytogenetic profiles (Pathak et al. 1997). iii) Interaction with pre-osteoclasts promotes osteoclastogenesis, increases bone turnover, and releases soluble and insoluble factors from the skeleton, supporting cancer growth and survival in bone. Our data collectively indicate that autocrine and paracrine RANKLRANK signaling is critical for the development of bone and soft tissue metastases in mice.

RANKL is expressed by inflammatory $\mathrm{T}$ and $\mathrm{B}$ cells, osteoblasts, marrow stromal cells, mesenchymal stem cells, and stromal fibroblasts (Thomas et al. 2001). RANKL expression can be regulated by endocrine factors and dietary cholesterol (Sanbe et al. 2009). The functional roles of RANKL depend on the triad relationship of inoculation of either luciferase-tagged LN ${ }^{\text {RANKL }}$ cells followed by intracardiac inoculation of $\mathrm{LN}^{\mathrm{Neo}-\mathrm{RFP}}$ cells to test the homing potential of RFP-tagged LNCaP ${ }^{\mathrm{Neo}}$ cells. (C) IHC and fluorescence images were obtained from chimeric tumors induced in mouse skeleton by inoculating 1000 LN $^{\text {RANKL }}$ cells plus $1 \times$ $10^{6} \mathrm{LN}^{\mathrm{Neo}-\mathrm{RFP}}$ cells. Representative IHC and fluorescence images of the tumors were merged ( $200 \times$ magnification). Data show co-localization of RFP cells with RANKL, c-Met, and p-c-Met expression in prostate tumors from mouse skeleton. (D) LN ${ }^{\text {Neo-RFP }}$ cells harvested from chimeric tumors (tumor LN $^{\text {Neo-RFP }}$ ) acquired EMT, neuroendocrine, and stem cell properties demonstrated by relative expression of markers detected by qRT-PCR $\left({ }^{*} P<0.05 ;{ }^{*} P<0.01\right.$; and $* * * P<0.001)$. (E) Representative bioluminescent images demonstrated tibial tumor formation induced by luciferase-tagged tumor-derived LN ${ }^{\text {Neo-RFP }}$ cells but not by luciferase-tagged parental $\mathrm{LN}^{\text {Neo-RFP }}$ cells (total flux (photons/s): parental LN ${ }^{\text {Neo-RFP-Luc }}, 5.77 \times 10^{3} ; 2.09 \times 10^{4} ;$ and $1.56 \times 10^{4}$ and tumor LN ${ }^{\text {Neo-RFP-Luc }}, 5.35 \times 10^{6} ; 9.94 \times 10^{5}$; and $8.52 \times 10^{5}$ ).

RANKL, RANK, and OPG where RANKL activity is modulated by the presence of RANK receptor and OPG (Ando et al. 2008). The pathophysiological significance of our findings is that RANKL expression is affected by inflammation and significantly augmented by hormonal deprivation (Li et al. 2009) or increased dietary cholesterol (Nuche-Berenguer et al. 2011). Interestingly, cancer bone and soft tissue dissemination is also known to be increased by inflammatory infiltrates in tumors. Increased cancer metastases were also observed in patients with higher dietary cholesterol and hosts undergoing androgendeprivation therapy (Tan et al. 2011).

Coordinated cell signal network expansion downstream from RANKL-RANK in PCa cells is associated with the invasive phenotype that commonly develops in CRPC patients upon disease progression or under hormonal or chemotherapeutic intervention (Mulholland et al. 2012). Our current model suggests that the RANKL-RANKmediated signal network downregulates AR and renders the PCa cells more aggressive and metastatic, including the ability to recruit and transform non-metastatic

Published by Bioscientifica Ltd. 
bystander cells. While the exact mechanisms by which AR downregulation promotes $\mathrm{PCa}$ aggressiveness is unknown, it has however been observed that approximately $25 \%$ of CRPC patients actually lose AR expression and develop rapid progressive bone metastasis. These patients express low levels of AR and PSA but have been observed to exhibit explosive metastatic disease clinically. Our study raises several important questions that require further study in clinical settings. Can $\mathrm{LN}^{\mathrm{RANKL}}$ cells be identified in the primary, at metastatic sites, or in the systemic circulation and be selectively or more effectively targeted based on their unique phenotype? As androgen deprivation can induce PCa stem cell and neuroendocrine differentiation, can androgen deprivation also induce the resurgence of PCa cells with a phenotype resembling $\mathrm{LN}^{\mathrm{RANKL}}$ ? Can the dietary cholesterol, hormonal or inflammatory status of patients be modulated to reduce overall levels of RANKL or RANKL-RANK signaling, to minimize the tumor cell population that initiates PCa metastasis, thus reducing tumor recurrence and distant dissemination? A better understanding of RANKL-RANK signaling in clinical cancer metastasis will improve cancer bone targeting and patient survival.

In summary, our results indicate that RANKL, either derived from the tumor or from the host, plays a key role in cancer bone metastasis. A small population of $\mathrm{LN}^{\mathrm{RANKL}}$ cells was observed to initiate and promote cancer bone and soft tissue metastases by recruiting bystander cells to form tumors in bone. The mechanism underlying this recruitment appears to involve a feed-forward mechanism in which RANKL, RANK, and c-Met expression is increased and AR is downregulated. RANKL alters a large transcriptional program that appears to govern formation of the premetastatic niche as well as emergence of osteomimetic, EMT, and stem and neuroendocrine differentiation. Our results raise a new paradigm beyond the clonal expansion and evolution of cancer cells, where a population of metastasis-initiating PCa cells recruits and activates bystander cells, including 'dormant' cancer cells, through RANK-mediated signal amplification.

\section{Supplementary data}

This is linked to the online version of the paper at http://dx.doi.org/10.1530/ ERC-13-0548.

\section{Declaration of interest}

The authors declare that there is no conflict of interest that could be perceived as prejudicing the impartiality of the research reported.

\section{Funding}

This work was supported by NCI P01 grant (2P01CA098912), R01 grant (1R01CA122602), and a PCF Challenge Award.

\section{Acknowledgements}

The authors thank Dr Robert L Vessella, Departments of Urology and Microbiology, University of Washington, for kindly providing the human prostate cancer bone metastasis arrays; Dr Peizhen Hu, Department of Medicine, Cedars-Sinai Medical Center (CSMC), for determination of the Gleason grade of the tumors and the quantification of the staining; Dr Quanlin Li, Biostatistics and Bioinformatics Center, Cedars-Sinai Medical Center (CSMC), for statistical analyses; Drs Wafa Tawackoli and Xiaoyu Da, CSMC Research Imaging Core, for animal imaging and $\mu \mathrm{CT}$ analyses; Dr Neale Weitzmann, Division of Endocrinology, Emory University, for providing mouse RAW264.7 cells and the in vitro osteoclastogenesis assay protocol; and Mr Gary Mawyer for manuscript editing.

\section{References}

Akech J, Wixted JJ, Bedard K, van der Deen M, Hussain S, Guise TA, van Wijnen AJ, Stein JL, Languino LR, Altieri DC et al. 2010 Runx2 association with progression of prostate cancer in patients: mechanisms mediating bone osteolysis and osteoblastic metastatic lesions. Oncogene 29 811-821. (doi:10.1038/onc.2009.389)

Ando K, Mori K, Redini F \& Heymann D 2008 RANKL/RANK/OPG: key therapeutic target in bone oncology. Current Drug Discovery Technologies 5 263-268. (doi:10.2174/157016308785739857)

Birchmeier C, Birchmeier W, Gherardi E \& Vande Woude GF 2003 Met, metastasis, motility and more. Nature Reviews. Molecular Cell Biology 4 915-925. (doi:10.1038/nrm1261)

Cai J, Guan H, Fang L, Yang Y, Zhu X, YuanJ, Wu J \& Li M 2013 MicroRNA-374a activates Wnt/ $\beta$-catenin signaling to promote breast cancer metastasis. Journal of Clinical Investigation 123 566-579. (doi:10.1172/JCI65871)

Carro MS, Lim WK, Alvarez MJ, Bollo RJ, Zhao X, Snyder EY, Sulman EP, Anne SL, Doetsch F, Colman H et al. 2010 The transcriptional network for mesenchymal transformation of brain tumours. Nature 463 318-325. (doi:10.1038/nature08712)

Cole MD \& McMahon SB 1999 The Myc oncoprotein: a critical evaluation of transactivation and target gene regulation. Oncogene 18 2916-2924. (doi:10.1038/sj.onc.1202748)

Coleman RE 2001 Metastatic bone disease: clinical features, pathophysiology and treatment strategies. Cancer Treatment Reviews 27 165-176. (doi:10.1053/ctrv.2000.0210)

De Marzo AM, Knudsen B, Chan-Tack K \& Epstein JI 1999 E-cadherin expression as a marker of tumor aggressiveness in routinely processed radical prostatectomy specimens. Urology 53 707-713. (doi:10.1016/ S0090-4295(98)00577-9)

Dougall WC 2011 Molecular pathways: osteoclast-dependent and osteoclast-independent roles of the RANKL/RANK/OPG pathway in tumorigenesis and metastasis. Clinical Cancer Research 18 326-335. (doi:10.1158/1078-0432.CCR-10-2507)

Gherardi E, Birchmeier W, Birchmeier C \& Vande Woude G 2012 Targeting MET in cancer: rationale and progress. Nature Reviews. Cancer 12 89-103. (doi:10.1038/nrc3205)

Griffith OL, Montgomery SB, Bernier B, Chu B, Kasaian K, Aerts S, Mahony S, Sleumer MC, Bilenky M, Haeussler M et al. 2008 ORegAnno: an openaccess community-driven resource for regulatory annotation. Nucleic Acids Research 36 D107-D113. (doi:10.1093/nar/gkm967)

Hanada R, Leibbrandt A, Hanada T, Kitaoka S, Furuyashiki T, Fujihara H, Trichereau J, Paolino M, Qadri F, Plehm R et al. 2009 Central control of fever and female body temperature by RANKL/RANK. Nature $\mathbf{4 6 2}$ 505-509. (doi:10.1038/nature08596)

Published by Bioscientifica Ltd. 
Hiraga T, Myoui A, Hashimoto N, Sasaki A, Hata K, Morita Y, Yoshikawa H, Rosen CJ, Mundy GR \& Yoneda T 2012 Bone-derived IGF mediates crosstalk between bone and breast cancer cells in bony metastases. Cancer Research 72 4238-4249. (doi:10.1158/0008-5472.CAN-11-3061)

Hu P, Chung LW, Berel D, Frierson HF, Yang H, Liu C, Wang R, Li Q, Rogatko A \& Zhau HE 2013 Convergent RANK- and c-Met-mediated signaling components predict survival of patients with prostate cancer: an interracial comparative study. PLoS ONE 8 e73081. (doi:10.1371/ journal.pone.0073081)

Huang WC, Wu D, Xie Z, Zhau HE, Nomura T, Zayzafoon M, Pohl J, Hsieh CL, Weitzmann MN, Farach-Carson MC et al. 2006 $\beta 2$-Microglobulin is a signaling and growth-promoting factor for human prostate cancer bone metastasis. Cancer Research 66 9108-9116. (doi:10.1158/0008-5472.CAN-06-1996)

Huang WC, Zhau HE \& Chung LW 2010 Androgen receptor survival signaling is blocked by anti- $\beta 2$-microglobulin monoclonal antibody via a MAPK/lipogenic pathway in human prostate cancer cells. Journal of Biological Chemistry 285 7947-7956. (doi:10.1074/jbc.M109.092759)

Huang da W, Sherman BT \& Lempicki RA 2009 Systematic and integrative analysis of large gene lists using DAVID bioinformatics resources. Nature Protocols 4 44-57. (doi:10.1038/nprot.2008.211)

Hwang D, Rust AG, Ramsey S, Smith JJ, Leslie DM, Weston AD, de Atauri P, Aitchison JD, Hood L, Siegel AF et al. 2005 A data integration methodology for systems biology. PNAS 102 17296-17301. (doi:10.1073/pnas.0508647102)

Josson S, Nomura T, Lin JT, Huang WC, Wu D, Zhau HE, Zayzafoon M, Weizmann MN, Gururajan M \& Chung LW 2011 ß2-Microglobulin induces epithelial to mesenchymal transition and confers cancer lethality and bone metastasis in human cancer cells. Cancer Research $\mathbf{7 1}$ 2600-2610. (doi:10.1158/0008-5472.CAN-10-3382)

Jung P, Menssen A, Mayr D \& Hermeking H 2008 AP4 encodes a c-MYCinducible repressor of $p 21$. PNAS 105 15046-15051. (doi:10.1073/ pnas.0801773105)

Knudsen BS \& Edlund M 2004 Prostate cancer and the met hepatocyte growth factor receptor. Advances in Cancer Research 91 31-67. (doi:10.1016/S0065-230X(04)91002-0)

Kong D, Li Y, Wang Z \& Sarkar FH 2011 Cancer stem cells and epithelialto-mesenchymal transition (EMT)-phenotypic cells: are they cousins or twins? Cancer 3 716-729. (doi:10.3390/cancers30100716)

Lachmann A, Xu H, Krishnan J, Berger SI, Mazloom AR \& Ma'ayan A 2010 ChEA: transcription factor regulation inferred from integrating genome-wide ChIP-X experiments. Bioinformatics 26 2438-2444. (doi:10.1093/bioinformatics/btq466)

van Leenders GJ, Sookhlall R, Teubel WJ, de Ridder CM, Reneman S, Sacchetti A, Vissers KJ, van Weerden W \& Jenster G 2011 Activation of c-MET induces a stem-like phenotype in human prostate cancer. PLOS ONE 6 e26753. (doi:10.1371/journal.pone.0026753)

Li X, Ominsky MS, Stolina M, Warmington KS, Geng Z, Niu QT, Asuncion FJ, Tan HL, Grisanti M, Dwyer D et al. 2009 Increased RANK ligand in bone marrow of orchiectomized rats and prevention of their bone loss by the RANK ligand inhibitor osteoprotegerin. Bone $\mathbf{4 5}$ 669-676. (doi:10.1016/j.bone.2009.06.011)

Linhart C, Halperin Y \& Shamir R 2008 Transcription factor and microRNA motif discovery: the Amadeus platform and a compendium of metazoan target sets. Genome Research 18 1180-1189. (doi:10.1101/gr.076117.108)

Lu X, Mu E, Wei Y, Riethdorf S, Yang Q, Yuan M, Yan J, Hua Y, Tiede BJ, Lu X et al. 2011 VCAM-1 promotes osteolytic expansion of indolent bone micrometastasis of breast cancer by engaging $\alpha 4 \beta 1$-positive osteoclast progenitors. Cancer Cell 20 701-714. (doi:10.1016/j.ccr.2011.11.002)

McHugh NA, Vercesi HM, Egan RW \& Hey JA 2003 Receptor activator of $\mathrm{NF}-\mathrm{\kappa B}$ ligand arrests bone growth and promotes cortical bone resorption in growing rats. Journal of Applied Physiology 95 672-676. (doi:10.1152/japplphysiol.00056.2003)

Mulholland DJ, Kobayashi N, Ruscetti M, Zhi A, Tran LM, Huang J, Gleave M $\&$ Wu H 2012 Pten loss and RAS/MAPK activation cooperate to promote EMT and metastasis initiated from prostate cancer stem/progenitor cells. Cancer Research 72 1878-1889. (doi:10.1158/0008-5472.CAN11-3132)

Nadiminty N, Tummala R, Lou W, Zhu Y, Zhang J, Chen X, eVere White RW, Kung HJ, Evans CP \& Gao AC 2012 MicroRNA let-7c suppresses androgen receptor expression and activity via regulation of Myc expression in prostate cancer cells. Journal of Biological Chemistry 287 1527-1537. (doi:10.1074/jbc.M111.278705)

Nuche-Berenguer B, Lozano D, Gutierrez-Rojas I, Moreno P, Marinoso ML, Esbrit P \& Villanueva-Penacarrillo ML 2011 GLP-1 and exendin-4 can reverse hyperlipidic-related osteopenia. Journal of Endocrinology 209 203-210. (doi:10.1530/JOE-11-0015)

Odero-Marah VA, Wang R, Chu G, Zayzafoon M, Xu J, Shi C, Marshall FF, Zhau HE \& Chung LW 2008 Receptor activator of NF- $\kappa$ B Ligand (RANKL) expression is associated with epithelial to mesenchymal transition in human prostate cancer cells. Cell Research 18 858-870. (doi:10.1038/cr.2008.84)

Organ SL \& Tsao MS 2011 An overview of the c-MET signaling pathway. Therapeutic Advances in Medical Oncology 3 S7-S19. (doi:10.1177/ 1758834011422556)

Paland N, Kamer I, Kogan-Sakin I, Madar S, Goldfinger N \& Rotter V 2009 Differential influence of normal and cancer-associated fibroblasts on the growth of human epithelial cells in an in vitro cocultivation model of prostate cancer. Molecular Cancer Research 7 1212-1223. (doi:10.1158/1541-7786.MCR-09-0073)

Park SI, Soki FN \& McCauley LK 2011 Roles of bone marrow cells in skeletal metastases: no longer bystanders. Cancer Microenvironment 4 237-246. (doi:10.1007/s12307-011-0081-8)

Pathak S, Nemeth MA, Multani AS, Thalmann GN, von Eschenbach AC \& Chung LW 1997 Can cancer cells transform normal host cells into malignant cells? British Journal of Cancer 76 1134-1138. (doi:10.1038/ bjc.1997.524)

Portales-Casamar E, Kirov S, Lim J, Lithwick S, Swanson MI, Ticoll A, Snoddy J \& Wasserman WW 2007 PAZAR: a framework for collection and dissemination of cis-regulatory sequence annotation. Genome Biology 8 R207. (doi:10.1186/gb-2007-8-10-r207)

Qi J, Nakayama K, Cardiff RD, Borowsky AD, Kaul K, Williams R, Krajewski S, Mercola D, Carpenter PM, Bowtell D et al. 2010 Siah2-dependent concerted activity of HIF and FoxA2 regulates formation of neuroendocrine phenotype and neuroendocrine prostate tumors. Cancer Cell 18 23-38. (doi:10.1016/j.ccr.2010.05.024)

Qian BZ, Li J, Zhang H, Kitamura T, Zhang J, Campion LR, Kaiser EA, Snyder LA \& Pollard JW 2011 CCL2 recruits inflammatory monocytes to facilitate breast-tumour metastasis. Nature 475 222-225. (doi:10.1038/nature10138)

Reimand J, Arak T \& Vilo J 2011 g:Profiler - a web server for functional interpretation of gene lists (2011 update). Nucleic Acids Research 39 W307-W315. (doi:10.1093/nar/gkr378)

Sanbe T, Tomofuji T, Ekuni D, Azuma T, Irie K, Tamaki N, Yamamoto T \& Morita M 2009 Vitamin C intake inhibits serum lipid peroxidation and osteoclast differentiation on alveolar bone in rats fed on a highcholesterol diet. Archives of Oral Biology 54 235-240. (doi:10.1016/ j.archoralbio.2008.11.001)

Severin J, Waterhouse AM, Kawaji H, Lassmann T, van Nimwegen E, Balwierz PJ, de Hoon MJ, Hume DA, Carninci P, Hayashizaki Y et al. 2009 FANTOM4 EdgeExpressDB: an integrated database of promoters, genes, microRNAs, expression dynamics and regulatory interactions. Genome Biology 10 R39. (doi:10.1186/gb-2009-10-4-r39)

Sheridan C, Kishimoto H, Fuchs RK, Mehrotra S, Bhat-Nakshatri P, Turner CH, Goulet R Jr, Badve S \& Nakshatri H 2006 CD44 ${ }^{+} / \mathrm{CD} 24^{-}$ breast cancer cells exhibit enhanced invasive properties: an early step necessary for metastasis. Breast Cancer Research 8 R59. (doi:10.1186/ bcr1610)

Smith DC, Smith MR, Sweeney C, Elfiky AA, Logothetis C, Corn PG, Vogelzang NJ, Small EJ, Harzstark AL, Gordon MS et al. 2013 Cabozantinib in patients with advanced prostate cancer: results of a 
phase II randomized discontinuation trial. Journal of Clinical Oncology 31 412-419. (doi:10.1200/JCO.2012.45.0494)

Storey J \& Tibshirani R 2003 Statistical methods for detecting differential gene expression. In Functional Genomics: Methods and Protocols, pp 111-136. Eds MJ Brownstein \& AB Khodursky. Totowa, NJ: Methods in Molecular Biology series, 224 Humana Press.

Subramanian A, Tamayo P, Mootha VK, Mukherjee S, Ebert BL, Gillette MA, Paulovich A, Pomeroy SL, Golub TR, Lander ES et al. 2005 Gene set enrichment analysis: a knowledge-based approach for interpreting genome-wide expression profiles. PNAS 102 15545-15550. (doi:10.1073/pnas.0506580102)

Tan W, Zhang W, Strasner A, Grivennikov S, Cheng JQ, Hoffman RM \& Karin M 2011 Tumour-infiltrating regulatory T cells stimulate mammary cancer metastasis through RANKL-RANK signalling. Nature 470 548-553. (doi:10.1038/nature09707)

Thomas GP, Baker SU, Eisman JA \& Gardiner EM 2001 Changing $R A N K L / O P G$ mRNA expression in differentiating murine primary osteoblasts. Journal of Endocrinology 170 451-460. (doi:10.1677/ joe.0.1700451)

Verras M, Lee J, Xue H, Li TH, Wang Y \& Sun Z 2007 The androgen receptor negatively regulates the expression of c-Met: implications for a novel mechanism of prostate cancer progression. Cancer Research 67 967-975. (doi:10.1158/0008-5472.CAN-06-3552)
Wu Z, Irizarry R, Gentleman R, Murillo F \& Spencer F 2004 A model based background adjustment for oligonucleotide expression arrays. Journal of the American Statistical Association 99 909-917. (doi:10.1198/ 016214504000000683)

Xu J, Wang R, Xie ZH, Odero-Marah V, Pathak S, Multani A, Chung LW \& Zhau HE 2006 Prostate cancer metastasis: role of the host microenvironment in promoting epithelial to mesenchymal transition and increased bone and adrenal gland metastasis. Prostate 66 1664-1673. (doi:10.1002/pros.20488)

Yang X, Shi C, Tong R, Qian W, Zhau HE, Wang R, Zhu G, Cheng J, Yang VW, Cheng T et al. 2010 Near IR heptamethine cyanine dye-mediated cancer imaging. Clinical Cancer Research 16 2833-2844. (doi:10.1158/1078-0432.CCR-10-0059)

Zhao F, Xuan Z, Liu L \& Zhang MQ 2005 TRED: a Transcriptional Regulatory Element Database and a platform for in silico gene regulation studies. Nucleic Acids Research 33 D103-D107. (doi:10.1093/ nar/gki004)

Zhau HE, Odero-Marah V, Lue HW, Nomura T, Wang R, Chu G, Liu ZR, Zhou BP, Huang WC \& Chung LW 2008 Epithelial to mesenchymal transition (EMT) in human prostate cancer: lessons learned from ARCaP model. Clinical \& Experimental Metastasis 25 601-610. (doi:10.1007/s10585-008-9183-1)

Received in final form 23 December 2013

Accepted 6 January 2014
Published by Bioscientifica Ltd. 